\title{
How to allocate forward contracts: The case of electricity markets
}

\author{
María-Ángeles de Frutos*, Natalia Fabra \\ Department of Economics, Universidad Carlos III de Madrid, Calle Madrid 126, 28903 Getafe, Madrid, Spain
}

\section{A R T I C L E I N F O}

JEL classification:

L13

L94

G13

Keywords:

Forward contracts

Discrete supply functions

Electricity markets

Antitrust remedies

Simulations

\begin{abstract}
A B S T R A C T
Several regulatory authorities worldwide have imposed forward contract commitments on electricity producers as a way to mitigate their market power. In this paper we analyze the impact of such commitments on equilibrium outcomes in a model that reflects important institutional and structural features of electricity markets. We show that, when firms are asymmetric, the distribution of contracts among firms matters. In the case of a single dominant firm, the regulator can be confident that allocating contracts to that firm will be pro competitive. However, when asymmetries are less extreme, certain contract allocations might yield anti competitive outcomes by elim inating more competitive equilibria. Our analysis thus suggests that forward contracts should be allocated so as to (virtually) reduce asymmetries across firms.
\end{abstract}

\section{Introduction}

Concerns over the exercise of market power in electricity markets have led several competition and regulatory authorities to impose forward contract commitments on the dominant producers. Such contracts have taken various forms, but they all have one important feature in common: they commit producers to receive a fixed price for a certain fraction of their output before wholesale market competition takes place. The 'vesting contracts' introduced at privatization in the British electricity market or the 'Competition Transition Costs' for stranded costs recovery in Spain, provide two well known examples of such forward commitments. ${ }^{1}$ More recently, several regulators worldwide have been forcing large electricity producers to auction off 'virtual power plants' (VPPs), which essentially work as forward sales. VPPs have also been used as antitrust remedies in several competition policy cases, including merger control proceedings and abuse of dominance investigations. ${ }^{2}$ More generally, several authors have blamed the poor performance of some electricity markets on the lack of sufficient forward contracting, and propose to foster it for these markets to deliver efficient outcomes (Wolak, 2012; Bushnell et al., 2008).

\footnotetext{
*Corresponding author. Tel.: +3491 6249600; fax: +34916249329.

E-mail address: frutos@eco.uc3m.es (M.-Á. de Frutos).

1 See Wolfram (1999) for a description of the first, and Fabra and Toro (2005) and Kühn and Machado (2006) for a description of the second.

2 For instance, VPPs have been used in the merger cases EDF/EnBW in 2000 and Nuon/Reliant in 2003, in the alleged price-squeeze case involving EDF/Direct Energy in 2007, or in the abuse of dominance by ENEL in 2006. In Spain and Portugal, VPPs have also been used in an attempt to make the market more competitive. For a description and analysis of VPPs, see Ausubel and Cramton (2010), Federico and López (2009) and Schultz (2009). Some unconventional forms of forward contracts have been used in other competition policy settings, such as certain voluntary operating restrictions adopted by firms in antitrust lawsuits, see Borenstein (1996).
} 
Despite the policy activity surrounding the use of forward contracts, there has been relatively little exploration of what the optimal set of forward contract commitments might be. This paper addresses this topic by modelling the interplay of forward contracts with equilibrium outcomes in auction based spot markets. The key result is that the allocation of contracts among firms is a critical issue when firms are asymmetric. For instance, whereas it is pro competitive to force the dominant producers to selling forward contracts, it is anti competitive to impose such obligation on medium sized firms. Similarly, encouraging the medium sized firms to purchase forward contracts is pro competitive, but allowing the dominant producers to do so is anti competitive. ${ }^{3}$

In practice, forward obligations are typically imposed on large producers to prevent them from exploiting their market power the main examples being the VPPs on EDF in France, and the VPPs on Endesa and Iberdrola in Spain. However, there are also instances in which forward obligations are imposed on medium sized firms a recent example being the VPP proposed as a remedy of the merger between Gas Natural and Unión Fenosa in Spain. Also, it is not common practice that competitors of dominant firms are encouraged or obliged to buy forward contracts on the contrary, in some cases, they are not even allowed to do so, as in the VPPs in Spain and the Netherlands. ${ }^{4}$ Our paper thus suggests that forward contract obligations could potentially be a more effective tool than currently used in practice.

Our analysis reflects important institutional and structural features of electricity markets. Firstly, firms compete by submitting supply functions with a finite number of steps, as it is the case in many electricity markets in practice; ${ }^{5}$ secondly, firms own a portfolio of several production technologies, thus giving rise to (weakly) increasing marginal cost functions that might differ across firms; and thirdly, firms are allowed to hold exogenously given forward contracts, which are financially settled once the market closes. ${ }^{6}$

Despite the complexity of the problem, we show that all the equilibria have a simple pattern: all firms but one (referred to as non price setters) behave as price takers, i.e., they produce the same as if they bid at marginal costs, while the remaining firm (referred to as the price setter) sets the price at the level that maximizes its profits over the residual demand (Theorem 1). ${ }^{7}$ Therefore, there are as many candidate equilibrium outcomes as firms in the market, all of which differ in the identity of the price setter. Nevertheless, not all candidate equilibria might be sustainable. A price taker might have incentives to deviate from any candidate equilibria at which the price setter chooses a very low price: by deviating it would lose output, but such output loss might be more than compensated by the price increase. This limits the set of firms that can act as price setters in equilibrium. The equilibrium set is nevertheless non empty, as no firm wants to deviate from the highest price candidate equilibrium. In general, the resulting equilibria cannot be Pareto ranked as, all else equal, firms prefer to be non price setters rather than price setters.

The main results of the paper are contained in Proposition 4, which shows that the impact of forward contracts on equilibrium prices derives from two effects: the change in the price setter's profit maximizing price and the change in the non price setters' deviation incentives. On the one hand, the price setter's profit maximizing price is lower with contracts given that market prices only affect its uncovered sales. On the other hand, a lower price also makes it more attractive for a non price setter to deviate to a higher price. If contracts are symmetrically distributed across symmetric firms, the only relevant effect of contracts is the one on the price setter's profit maximizing price. Hence, an increase in contracts up to firms' competitive quantities is unambiguously pro competitive. However, this prediction may be reversed when firms are asymmetric, as the effects of contracts on the non price setters' deviation incentives, and thus on equilibrium existence, start to play a role. Indeed, a novel result from the paper namely, that an increase in the contract coverage of the price setter can lead to higher prices comes exactly from the impact of contracts on equilibrium existence. The increase in the price setter's contract coverage, which lowers its profit maximizing price, may trigger a deviation by some other firm, thus making such equilibrium disappear. This result is therefore related to a shrinking of the set of equilibrium outcomes and is not a standard type of comparative static result.

The above conclusions support the main message of the paper: since contract distribution and contract volume are crucial in determining the effects of forward contracts, there is scope for making them pro competitive. In markets with large asymmetries across firms, only the dominant firm should be forced to hold forward contracts; getting contract volume right is less critical, as contracts in this case would at worst be ineffective. Regulators should be more cautious in the presence of mild asymmetries between large and medium sized firms, as it is in such cases when the potential anti competitive effects of contracts are more likely to arise. Still, it is in these contexts when contracts may have a stronger role to play, as encouraging the smaller firms to purchase such contracts may further mitigate the market power of dominant firms.

\footnotetext{
${ }^{3}$ These suggestions go in line with Ausubel and Cramton's (2010), who argue that the "buyers of VPP contracts are ideally competitors", and that the main distinction between VPPs and forward markets is that the former "are normally placed on the dominant firm", while the latter "should extend to all generators."

${ }^{4}$ The medium-sized firms EDP and Unión Fenosa were not allowed to participate in the Spanish VPPs. Similarly, Electrabel and Essent were not initially allowed to participate in the VPPs in the Netherlands (Essent objected to being excluded from the auction and the court finally allowed it to participate).

${ }^{5}$ An exception is the Nord Pool, where bidders submit piecewise linear bid functions.

${ }^{6}$ Nyborg and Strebulaev (2004) also study auctions where bidders have exogenously given forward contracts. However, in that paper short-sellers face the risk of being squeezed in the secondary market, thus affecting the auction itself. Short-squeezes are not an issue in our setting as electricity markets are typically very liquid and most contracts are settled by differences with respect to the spot market price.

${ }^{7}$ Using data from the UK electricity market, Crawford et al. (2007) have shown that this pattern of asymmetric bidding is observed in practice.
} 
In order to illustrate our theoretical results, we have performed a simulation exercise that uses a rich data set of the Spanish electricity market. Assuming that contract volume remains fixed while demand varies over the year, the analysis shows that the pro competitive effect of contracts dominates over the anti competitive one. Still, the latter shows up in the simulations at certain hours, depending on contract volume and contract allocation.

There is already a large body of theoretical work on the impact of forward trading on the performance of oligopolistic markets. ${ }^{8}$ However, existing papers are not fully applicable to the problem at hand, to the extent that they assume that ex ante symmetric firms choose their contracts prior to competing either à la Cournot (Allaz and Vila, 1993; Bushnell, 2007) or à la Bertrand (Mahenc and Salanié, 2004). ${ }^{9}$ Instead, forward contract commitments are not endogenously chosen by firms but rather imposed by regulators. Also, costs and capacity asymmetries are pervasive among electricity producers. These two differences explain why and when our predictions differ. In the existing papers, and regardless of whether firms compete à la Cournot or à la Bertrand, forward sales (purchases) induce firms to compete (less) more fiercely given that spot market prices only affect their net selling (net buying) positions. However, once contracts are endogenized, the Cournot model predicts that contracts are pro competitive because all firms are net sellers at the subgame perfect equilibrium, whereas the opposite holds true under the Bertrand model. In contrast, our model predicts that exogenously given contracts might have anti competitive effects even if firms are net sellers.

As a by product, our analysis also contributes to the literature on share auctions. In a common value setting, Wilson (1979) shows that there exist equilibria with prices below the common value. Kremer and Nyborg (2004) demonstrate that these kind of equilibria can be eliminated in a discrete setting, similar to the one employed in the current paper, where quantities must be discrete though prices need not. Restricting bidders to submit a finite number of price quantity pairs implies that there is a positive mass at the margin, so that competition for the margin destroys the underpricing equilibria found by Wilson. In the current paper, in contrast, bidders can exploit the fact that (weakly) increasing marginal costs lead to downward sloping residual demand functions, in the same way as bidders can engage in demand reduction in a setting à la Wilson (see also Ausubel and Cramton, 2002). In sum, by relaxing the flat common value assumption, our paper recovers the inefficiencies in Wilson in a discrete setting à la Kremer and Nyborg. ${ }^{10}$

The paper is structured as follows. In Section 2 we describe the general model, a simple example of which is solved in Section 3. Section 4 is devoted to the analysis of the general model, including the characterization of firms' optimal behavior, equilibrium outcomes, equilibrium existence and multiplicity, and the impact of forward contracts. Section 5 contains a simulation exercise, while Section 6 concludes.

\section{Description of the model}

We consider a model in which $N \geq 2$ firms compete to supply a perfectly divisible good. Market demand, $D(p)$, can be either price inelastic or downward sloping, $D^{\prime}(p) \leq 0$, and its inverse function is denoted $P(q)$.

Firm $n$ 's productive capacity $K_{n}, n=1, \ldots, N$, is made up of several units. Each unit has constant marginal costs of production up to its capacity limit. We impose no constraints on the number of units firms have (other than it must be finite), and allow for all types of asymmetries (both in size and cost) among the units owned by a firm, as well as across firms. By stacking firm n's units in increasing cost order, we construct its marginal cost curve, $c_{n}(q)$, which is a left continuous non decreasing step function. We use $C_{n}(q)$ to denote firm $n$ 's cost function, i.e., $C_{n}(q)=\int_{0}^{q} c_{n}(z) d z$. We assume that aggregate capacity in the market is always enough to cover total demand. In line with the literature on electricity auctions, we assume that information on firms' costs is complete because electricity generators share similar production technologies, and are thus well aware of the efficiencies of their plants and the cost of the fuels.

Firms compete by simultaneously submitting a finite number of price quantity pairs. Prices cannot exceed the 'market reserve price' $p^{R}$ (which, for simplicity but without loss of generality, is assumed to exceed the highest marginal cost), and firms cannot produce above their capacities. Note that restricting firms to submit a finite number of price quantity pairs implies that firms' strategies are left continuous non decreasing step functions with a finite number of steps. We assume that both the "height" (prices) and "length" (quantities) of the steps are continuous choice variables.

By ordering firms' price quantity pairs in increasing price order, we construct their bid functions, i.e., for firm $n$,

$$
b_{n}=\left\{\left(p_{n s}, q_{n s}\right)\right\}_{s}^{\bar{s}} \quad 1, \quad p_{n s} \in\left[0, p^{R}\right] \quad \text { with } p_{n s+1} \geq p_{n s}, \quad q_{n s+1} \geq q_{n s} \quad \text { with } q_{n \bar{s}} \leq K_{n},
$$

where $\bar{s}<\infty$ is the maximum number of admissible steps in a firm's bid function. Consistent with actual rules in electricity markets, we will assume that the number of admissible steps does not constrain firms from bidding each unit at its own

\footnotetext{
${ }^{8}$ There is also an extensive empirical literature which confirms that contracts affect the performance of spot markets. See Bushnell et al. (2008), Fabra and Toro (2005), Hortacsu and Puller (2008), Kühn and Machado (2006), Mansur (2007), Wolak (2000) or Wolak (2007).

${ }^{9}$ Green (1999), Newbery (1998) and, more recently, Holmberg (2011) obtain mixed results in models in which firms compete by choosing continuous supply functions. Various papers analyze the dynamic effects of contracts (Ferreira, 2003; Green and Le Coq, 2010; Liski and Montero, 2006), and tend to conclude that they have anti-competitive effects.

${ }^{10}$ To be sure, the reasons why we recover the underpricing equilibria are similar to the ones that explain why the competitive outcome is not sustainable under Bertrand competition with capacity constraints, even though it constitutes the unique equilibrium outcome under pure Bertrand competition. Within the electricity auctions literature, simplified versions of our model also lead to a similar prediction (von der Fehr and Harbord, 1993; García-Díaz and Marín, 2003; Fabra et al., 2006; Crawford et al., 2007).
} 
marginal cost, i.e., $\bar{s}$ is large enough so as to allow firms to at least replicate their marginal cost curves. ${ }^{11}$ At each step $s$ in firm $n$ 's bid function, $p_{n s}$ specifies the minimum price at which the firm is willing to produce up to quantity $q_{n s}$. For a given bid profile $b=\left\{b_{n}\right\}_{n}^{N}{ }_{1}$, we construct the aggregate supply function, denoted $S(q)$, which determines the lowest price at which all firms in the market are willing to produce up to quantity $q$.

The market price, $p^{*}$, at which all transactions take place, is defined as follows:

$$
p^{*}=\max _{q}\{p=S(q) \mid S(q) \leq P(q)\}
$$

In words, the market price $p^{*}$ is the point on the aggregate supply function, $S(q)$, at which the market clears. If the demand function $P(q)$ is downward sloping, it need not always intersect the (possibly) discontinuous aggregate supply function, in which case $p^{*}$ is the highest price on the aggregate supply function at which there is excess demand. In contrast, if demand is inelastic, there are potentially many market clearing prices when the demand function intersects the supply function at the right end of an step. In this case, $p^{*}$ is the lowest price at which the market clears, given that it must be on the (left continuous) aggregate supply function. ${ }^{12}$

Firms are called to produce in increasing price order up to $p^{*}$. We use $q_{n}^{*}$ to denote the quantity allocated to firm $n$. If there is excess supply at $p^{*}$, we assume efficient rationing on the margin, i.e., if several units have been bid at $p^{*}$, they split residual demand proportionally to the quantities offered at exactly $p^{*}$, unless their marginal costs differ, in which case the low cost units are dispatched first. ${ }^{13}$ By using efficient rationing, the set of equilibria of our game approximates the set of equilibria of a game in which rationing pro rata on the margin is used but where firms choose their bid prices on a finite grid, which is what occurs in real markets. Note that if rationing pro rata on the margin were assumed in our set up, it would lead to a problem of non existence of equilibrium similar to the one that arises under a Bertrand game with asymmetric costs.

We label prices and quantities as either competitive or non competitive. The competitive price, denoted $p^{c}$, is the point on the aggregate marginal cost function at which demand and competitive supply intersect. As before, if they do not intersect, we assume that $p^{c}$ is the highest price at which there is excess demand. The resulting competitive quantities are denoted $\left(q_{1}^{c}, \ldots, q_{N}^{c}\right)$. All other prices and quantities are referred to as non competitive. Similar labels are used to classify market outcomes.

An important feature of the model is that firms might be subject to forward contracts. We use $\tau_{n}$ to denote firm $n$ 's contract price, and $x_{n} \geq 0$ to denote firm $n$ 's contract quantity; both $\tau_{n}$ and $x_{n}$ are fixed when firms submit their bids. Consequently, when the market price is $p^{*}$ and firm $n$ 's dispatched quantity is $q_{n}^{*}$, firm $n$ 's profits are given by

$$
\pi_{n}\left(p^{*}, q_{n}^{*}\right)=p^{*} q_{n}^{*} C_{n}\left(q_{n}^{*}\right)+\left[\begin{array}{ll}
\tau_{n} & p^{*}
\end{array}\right] x_{n},
$$

where the first two terms give the firm's market profits, and the last term gives the firm's contract profits. To fix ideas, one can think of these contracts as being purely financial, i.e., firm $n$ continues to supply all its quantity $q_{n}^{*}$ to the market at $p^{*}$ and the contract's counterpart, e.g. a big customer, continues to buy all its demand from the market at $p^{*}$. The contract requires firm $n$ to pay (receive) the difference between the contract price and the market price times the contract quantity, $\left[\begin{array}{ll}\tau_{n} & p^{*}\end{array}\right] x_{n}$, whenever positive (negative). Re writing the above expression as

$$
\pi_{n}\left(p^{*}, q_{n}^{*}\right)=p^{*}\left[\begin{array}{ll}
q_{n}^{*} & x_{n}
\end{array}\right] C_{n}\left(q_{n}^{*}\right)+\tau_{n} x_{n}
$$

shows that firms' bidding incentives depend on their net positions, $\left[\begin{array}{ll}q_{n}^{*} & x_{n}\end{array}\right]$, which are positive for the net sellers, $q_{n}^{*}>x_{n}$, and negative for the net buyers, $q_{n}^{*}<x_{n}$. The last term, $\tau_{n} x_{n}$, is fixed when firms compete in the spot market; as such, it has no effect on bidding incentives (indeed, one could set $\tau_{n}=0$ without loss of generality). We will assume that total contract volume never exceeds demand at the competitive price, $\sum_{n} x_{n} \leq D\left(p^{c}\right)$, thus ruling out the cases in which $x_{n} \geq q_{n}^{c}$ holds for all firms $n$ (with at least one strict inequality).

Firm n's problem is to choose a finite number of price quantity pairs that maximize $\pi_{n}$ given its rivals' supply functions. We focus on Nash equilibria in pure strategies. All aspects of the model are common knowledge among firms. ${ }^{14}$

Before we proceed, it is convenient to set some terminology and notation. We first define which firms are marginal.

\footnotetext{
${ }^{11}$ The limit on the number of bids is typically set for each production unit rather than at the firm level. For instance, in the original market design in England and Wales, firms were allowed to submit up to three incremental prices per unit; up to 25 price-quantity pairs per unit in Spain; and up to 40 per unit in Texas. In practice, firms use even fewer bidpoints than the ones they are allowed to (Hortacsu and Puller, 2008).

12 These assumptions are consistent with most auction rules in practice. For instance, in the Spanish electricity market, demand bids cannot determine the market price (see www.omel.es). There are exceptions to this rule, particularly in US markets, which now clear prices with demand when all supply offers are exhausted (this is referred to as scarcity pricing). However, this possibility does not arise in our model given that there is always enough aggregate capacity to cover total demand. Last, the fact that the auctioneer chooses the lowest market-clearing price whenever there are multiple market-clearing prices is reasonable to the extent that it is the most favorable one from consumers' point of view. This is also assumed in Kremer and Nyborg (2004) and Kastl (2011).

13 Several papers in the electricity auctions literature assume efficient rationing on-the-margin as well (see, for instance, García-Díaz and Marín, 2003; Fabra et al., 2006, among others).

${ }^{14}$ When applied to electricity markets, it could be argued that firms face demand uncertainty (or demand variation) at the bidding stage. However, this issue depends on the duration of bids as compared to the frequency of market clearing: for instance, when firms submit supply functions that remain valid for a single period of market clearing, there will be little or no relevant variation in demand; however, with bids that remain good for a whole day, demand will vary considerably over the pricing period. Accordingly, our paper applies to the first case, which is the one in place in most electricity markets in practice. Last, the contracting stage may be affected by demand variation, as contracts typically remain fixed for longer periods of time.
} 
Definition 1. For an arbitrary bid function profile resulting in an outcome $\left\{p^{*} ;\left(q_{1}^{*}, \ldots, q_{N}^{*}\right)\right\}$, firm $n$ is marginal if its bid function has some step $s$ at the market price, $p_{n s}=p^{*}$.

We use the above definition to also classify firms as either price setters or non price setters:

Definition 2. For an arbitrary bid function profile resulting in an outcome $\left\{p^{*} ;\left(q_{1}^{*}, \ldots, q_{N}^{*}\right)\right\}$, firm $n$ is a price setter if it is a marginal firm and if it is at least partly dispatching its marginal step, $q_{n}^{*} \in\left(q_{n s-1}, q_{n s}\right]$. Otherwise, firm $n$ is a non price setter.

Finally, both the market price and the dispatched quantities depend on the demand, $D(p)$, and the bid function profile, $b$. However, in order to simplify notation, we suppress these arguments whenever clear from the context.

\section{Illustrative example}

We start by analyzing a simple example to convey the intuitions of the main results of the paper. In particular, we fix $N=2$ and assume that demand is perfectly inelastic at $D=3$. There exist four types of units, each with capacity normalized to one, whose marginal costs are $0,1,2$ or 2.5 . Firm 1 owns four units, one of each cost type, while firm 2 only has three units, not owning the unit with marginal costs 2. More specifically, their marginal cost functions are $c_{1}=\{(0,1),(1,2),(2,3),(2.5,4)\}$ and $c_{2}=\{(0,1),(1,2),(2.5,3)\}$. Accordingly, firms 1 and 2 will be respectively referred to as the "large firm" and the "small firm". Finally, we assume without loss of generality that the contract price is zero, $\tau_{n}=0$. Figs. 1 and 2 depict firms' marginal cost functions together with the residual demand they face when the rival bids at marginal costs.

We first show that in the absence of contracts, the competitive outcome cannot be sustained in equilibrium. Suppose that both firms bid at marginal costs, $b_{n}=c_{n}, n=1,2$, so that the aggregate supply function is $S=\{(0,2),(1,4),(2,5),(2.5,7)\}$. Since the auctioneer has to dispatch three units to satisfy demand, the competitive outcome is $\left\{p^{c}=1 ;\left(q_{1}^{c}=1.5, q_{2}^{c}=1.5\right)\right\}$, with profits $\pi_{n}^{c}=1, n=1,2$ (area A in the figures). If firm 1 deviates to bidding all its units at 2.5 , i.e., $b_{1}^{\prime}=\{(2.5,4)\}$, the aggregate supply function becomes $S^{\prime}=\{(0,1),(1,2),(2.5,7)\}$, the market price is raised to $p^{*}=2.5$, and firms' dispatched quantities are $q_{1}^{*}=1$ and $q_{2}^{*}=2$ (by the efficient tie breaking rule, firm 1's first unit is dispatched at capacity, as it has lower marginal costs than any of the other units that tie at the margin). Thus, firm 1 makes a larger profit, $\pi_{1}^{\prime}=2.5>\pi_{1}^{c}$ (its profits increase by area $\mathrm{B}+\mathrm{C}$ in Fig. 1). Interestingly, firm 2's profits increase even more, $\pi_{2}^{\prime}=4$. Note that one can also rule out existence of a competitive equilibrium by letting firm 2 deviate from marginal cost bidding. In this case, firm 2 would optimally raise the price to 2 , e.g. by bidding at $b_{2}^{\prime}=\{(2,2),(2.5,3)\}$, in order to increase its profits to $\pi_{2}^{\prime}=2>\pi_{2}^{c}$ (its profits increase by area B in Fig. 2); again, the other firm gains even more, $\pi_{1}^{\prime}=3$. Thus, the competitive outcome cannot be sustained in equilibrium, unless firms used weakly dominated strategies, a possibility ruled out throughout the paper.

The two bid function profiles considered above, $\left\{b_{1}^{\prime}, c_{2}\right\}$ and $\left\{c_{1}, b_{2}^{\prime}\right\}$, are indeed an equilibrium. Under both profiles, one firm is setting the market price at the level that maximizes its profits over its residual demand (which coincides with the marginal cost of its rival's first undispatched unit), while the other firm cannot increase its profits as it is producing the maximum it can without incurring in losses. The two equilibria are not outcome equivalent, as the first results in a high price, $p^{*}=2.5$, while the second results in a lower price, $p^{*}=2$. However, none of them can be ruled out by appealing to payoff dominance arguments, given that each firm is strictly better off when the rival sets the price. To see this, recall that at the first equilibrium firms' profits are $\pi_{1}=2.5$ and $\pi_{2}=4$, whereas at the second firms' profits are $\pi_{1}=3$ and $\pi_{2}=2 .{ }^{15}$

Besides the two equilibria described above, there are many other equilibrium bid profiles; in particular, there exist several equilibria with both firms bidding some units above marginal costs. The reason for this multiplicity is that several bid profiles yield the same outcome. However, conditionally on the identity of the firm that sets the price, all equilibria are outcome equivalent to the two equilibria just described. In sum, even though the strategy space is quite large, we need to just focus on candidate equilibrium outcomes, of which there are at most as many as firms in the market.

To illustrate the impact of contracts, let us first allocate all contracts to the large firm, $x_{1} \in(1,2]>x_{2}=0$. If firm 2 bids at marginal costs, firm 1's profit maximizing price now equals $p^{*}=1$ rather than $p^{*}=2.5$. To see this, note that if firm 1 sets the market price at $p^{*}=2.5$, it now becomes a net buyer as its contracts exceed its equilibrium output, $x_{1}>q_{1}^{*}=1$. As such, it prefers to reduce the price to $p^{*}=1$ by e.g. bidding at marginal costs. Indeed, since marginal cost bidding allows firm 1 to save the price difference over its net buying position, its profits increase by $\left[\begin{array}{ll}1 & 2.5\end{array}\right]\left[\begin{array}{ll}1 & x_{1}\end{array}\right]>0$ (area $\mathrm{D}+\mathrm{E}$ in Fig. 1). Therefore, the equilibrium at which firm 1 sets the price at $p^{*}=2.5$ can no longer be sustained, whereas the equilibrium at which firm 2 sets the price at $p^{*}=2$ can still be sustained (firm 2's incentives are unchanged as it has no contracts, while firm 1 does not find it profitable to reduce the price as at this equilibrium it is a net seller, $x_{1} \leq q_{1}^{*}=2$ ). Since only the low price equilibrium outcome survives, allocating contracts to the large firm is pro competitive.

(footnote continued)

However, this has no effect on the bidding stage as long as the features described above are met (see Fabra et al., 2011, for a model in which firms face demand uncertainty at the capacity-investment stage).

${ }^{15}$ This also implies that both equilibria are coalition-proof (see Bernheim et al., 1987). 


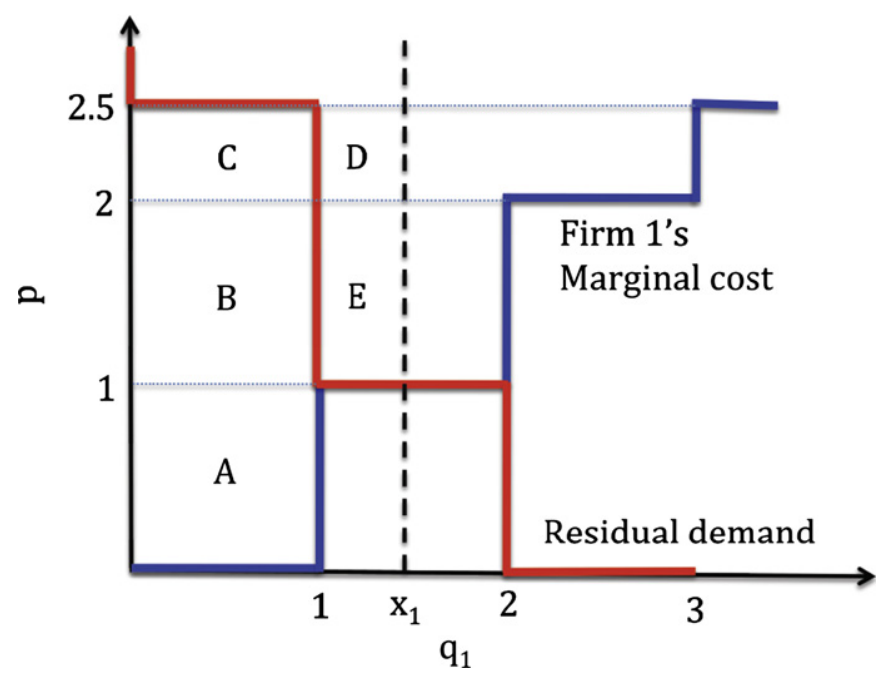

Fig. 1. Firm 1's marginal costs and residual demand in the example.

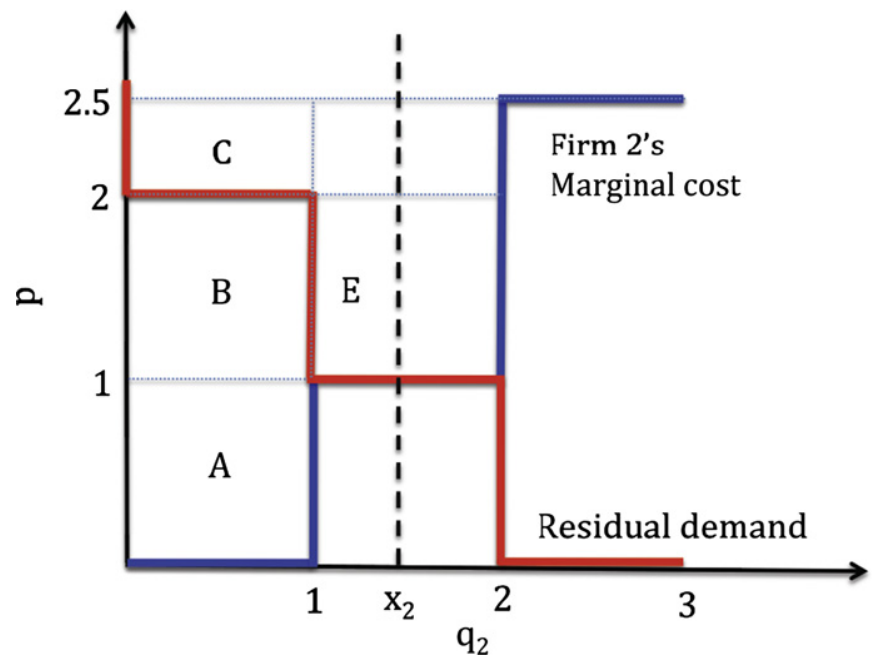

Fig. 2. Firm 2's marginal costs and residual demand in the example.

Table 1

Equilibrium prices as a function of firms' forward contract positions.

\begin{tabular}{|c|c|c|c|}
\hline \multirow[t]{2}{*}{ Cases } & \multicolumn{3}{|c|}{ Equilibrium prices } \\
\hline & No contracts & $x_{i} \in(1,2]>x_{j}$ & 0 \\
\hline Firm $i$ is large & $\{2.5,2\}$ & $\{\varnothing, 2\}$ & \\
\hline Firm $i$ is small & $\{2,2.5\}$ & $\{\varnothing, 2.5\}$ & \\
\hline
\end{tabular}

The first (second) term in brackets is the price that firm $i$ (firm $j$ ) would set in equilibrium when its rival behaves as a price-taker; there is an $\varnothing$ if such an equilibrium does not exist.

Alternatively, let us now allocate all contracts to the small firm, $x_{2} \in(1,2]>x_{1}=0$. By the same logic, the equilibrium with firm 2 setting the price at $p^{*}=2$ disappears: as a net buyer, firm 2 would rather bid at marginal costs in order to reduce the price from $p^{*}=2$ to $p^{*}=1$ and thus save the price difference over its net position, $\left[\begin{array}{lll}1 & 2\end{array}\right]\left[\begin{array}{ll}1 & x_{2}\end{array}\right]>0$ (area E in Fig. 2). However, firm 1 would then respond by setting the price at $p^{*}=2.5$, which implies that the only surviving equilibrium outcome is the one with the high price. Hence, forward contracts are anti competitive in this case. Table 1 summarizes these results. 


\section{Analysis of the model}

In this section, we characterize equilibrium bidding behavior and equilibrium outcomes in the general model. Rather than deriving equilibrium strategies, we instead deduce structural features that any equilibrium must have. As it is common in the analysis of uniform price auctions, we first refine the equilibrium set by restricting attention to strategies that are not weakly dominated.

Lemma 1. For firm $n$, it is weakly dominated (i) to bid below marginal costs for quantities above its contract cover, $q_{n}>x_{n}$, as well as (ii) to bid above marginal costs for quantities not exceeding its contract cover, $q_{n}<x_{n}$.

In words, weak dominance arguments eliminate below marginal cost bidding only for quantities above the firm's contract cover, $q_{n}>x_{n}$, i.e., such that the firm is a net seller. ${ }^{16}$ At lower quantities, the firm is a net buyer, and as such it would like to exercise monopsony power by bidding some units below marginal cost. Consistent with this, weak dominance arguments also eliminate above marginal cost bidding for quantities below the firm's contract cover, $q_{n}<x_{n}{ }^{17}$

In what follows, we will first fix the identity of the price setter in order to characterize the non price setters' optimal bidding behavior.

Lemma 2 (García Díaz and Marín, 2003). At any Nash Equilibrium in which firm $i$ is a price setter, all other firms $j, j \neq i$, are fully dispatching all their units with marginal costs strictly below the equilibrium price $p^{*}$.

The intuition underlying Lemma 2 is simple. Given that firm $i$ is dispatching some output at $p^{*}$, it cannot be the case that some other firm $j, j \neq i$, has some unit with marginal costs strictly below $p^{*}$ that has not been called to produce. If it instead bid such an undispatched unit slightly below $p^{*}$, firm $j$ would earn a positive profit margin over its increased production, with only (if any) a slight reduction in the price. Key to this result is the fact that firms submit a finite number of price quantity pairs, which implies that there is a positive output mass at the margin. Hence, when firm $j$ reduces its bid, the quantity gain always outweighs the price reduction as the latter can be made arbitrarily small.

Lemma 3. At any Nash Equilibrium in which firm $i$ is a price setter, firm $j, j \neq i$, is not dispatching any unit with marginal costs strictly above the equilibrium price $p^{*}$ if either one of the following two conditions holds ${ }^{18}$ :

(1) firm $j$ is a net seller or has a balanced position, i.e., $q_{j}^{*} \geq x_{j}$, or

(2) there is at least one marginal firm that is not fully dispatching its marginal step, i.e., $p^{*}=p_{k s}$ and $q_{k}^{*}<q_{k s}, k \neq j$.

By the elimination of weakly dominated strategies, net sellers cannot sell their marginal output below marginal costs. Similarly, firms with a balanced position do not find it profitable to bid below marginal costs in equilibrium given that by bidding at marginal costs they could save the difference between their marginal costs and the equilibrium price times their reduced output. Hence, $q_{j}^{*} \geq x_{j}$ is sufficient to guarantee that firm $j$ does not dispatch any unit with marginal costs below $p^{*}$.

The same result does not apply in general to an equilibrium in which firm $j$ is a net buyer, unless some other firm $k$ has bid some step at $p^{*}$ which has not been fully dispatched (i.e., $p^{*}=p_{k s}$ and $q_{k}^{*}<q_{k s}$ ). When this is the case, firm $j$ can avoid producing at a loss by bidding some of its output slightly above $p^{*}$, with no effect on the price. However, if all the marginal firms are fully dispatching their marginal steps, firm $j$ may be unable to reduce its production so as to avoid productive losses unless it raises the price high enough. As firm $j$ is a net buyer, the price increase which may no longer be infinitesimal may reduce the firm's profits (firm $j$ reduces productive losses but buys its negative net position at a higher price). There is hence no guarantee that at any equilibrium in which firm $i$ is a price setter, the other firms produce in an efficient manner unless they are all net sellers.

The next proposition combines the two lemmas above to provide conditions under which at any equilibrium the non price setters behave as if they were price takers.

Proposition 1. At any Nash Equilibrium in which firm i is a price setter, firm $j, j \neq i$, produces the same "as if" it were bidding at marginal costs if either one of the two conditions in the statement of Lemma 3 holds.

${ }^{16}$ Kastl (2011) shows that in discrete multi-unit uniform-price auctions, a rational bidder (without contracts) may submit a bid above its marginal valuation (in the current paper, a bid below marginal costs). This occurs only when the number of admissible steps in the bid functions is lower than the number of units, as it implies that bidders have to bundle bids for several units together. However, this does not arise in our paper given that, consistent with practice, bidders can at least submit as many bids as units they own.

${ }_{17}$ We cannot rule out either below or above marginal cost bidding for $q_{n} x_{n}$ because bid functions are step functions. With continuous bid functions instead, bidding $q_{n} \quad x_{n}$ at marginal costs would be a dominant strategy.

${ }^{18}$ In the absence of contracts, conditions (1) and (2) in the Lemma are not needed, since all firms would trivially be net-sellers. Indeed, without these two conditions, Lemma 3 is contained in García-Díaz and Marín's (2003) Corollary 1. 
The conditions under which Proposition 1 holds relate to equilibrium features, which are endogenous, such as the identity of the price setter or the non price setters' equilibrium net positions. Nevertheless, one can guarantee that at any equilibrium Proposition 1 always holds if all firms are net sellers at the competitive outcome. This condition relates to the primitives of the game, which are no longer endogenous.

To see why this is the case, note that weak dominance arguments imply that if $x_{n}<q_{n}^{c}$ holds for all firms, they must all bid their competitive quantities at or above marginal costs. Therefore, the equilibrium price $p^{*}$ cannot be lower than $p^{c}$. This implies that those firms that bid at marginal costs must be producing more than at the competitive outcome, and are thus net sellers; while those firms that bid above marginal costs must also be net sellers as a firm only bids above marginal costs for quantities above its contract cover (Lemma 1 (i)). Therefore, since condition (1) of Lemma 3 is satisfied, Proposition 1 applies.

In contrast, Proposition 1 does not generally hold if some firms are net buyers at the competitive outcome. First, since $p^{*} \leq p^{c}$ cannot be ruled out, even the firms that are bidding at marginal costs may produce below their competitive quantities, and hence remain/become net buyers. Moreover, even if $p^{*}>p^{c}$, and some firms expand production above their competitive quantities, such an increase in quantity might not be enough so as to exceed their contract positions.

For these reasons, it will be useful to analyze these two cases separately, which we respectively refer to as the regular cases (in which $x_{n}<q_{n}^{c}$ for all firms) and the irregular cases (in which $x_{n}<q_{n}^{c}$ holds for some but not all firms). The regular cases are the empirically most relevant ones given that, in practice, regulators never force firms to holding contracts above their competitive quantities. ${ }^{19}$

We start the analysis of the regular cases by identifying conditions under which the competitive outcome constitutes the unique equilibrium outcome of the game.

Proposition 2. Let $x_{n}<q_{n}^{c}$ hold for all firms.

(i) If every possible combination of ( $N$ 1) firms can jointly serve total demand at the competitive price, then the unique equilibrium outcome is the competitive one, i.e., $p^{*}=p^{c}$ and $q_{n}^{*}=q_{n}^{c}$ for all $n$.

(ii) Whenever there is supply rationing at $p^{c}$, any Nash equilibrium results in the competitive outcome if and only if there is more than one price setter.

If every possible combination of $\left(\begin{array}{ll}N & 1\end{array}\right)$ firms can jointly serve total demand at the competitive price, the residual demand faced by the $N$ th firm would fall down to zero if it deviated optimally from the competitive equilibrium. Hence, all firms have no option but to behave competitively. Note, however, that while the condition in part (i) of Proposition 2 is sufficient for the competitive outcome to emerge, it is nevertheless not necessary. If this condition did not hold, the Nth firm would have the possibility of manipulating the price up a notch. But if such a firm is not marginal, then it is making strictly positive profits out of all its dispatched units, so that it might not find profitable to deviate as the losses from reducing output might exceed the gains due to the price increase.

But for knife edge cases with no supply rationing at $p^{c, 20}$ the coexistence of multiple price setters is both necessary and sufficient for the competitive outcome to be sustainable. If there was only one price setter, its bid would determine the market price, and the firm would have incentives to engage in supply reduction. The upshot of this is that with multiple price setters, the equilibrium must be competitive as any of them would otherwise gain by slightly undercutting the price in order to achieve a positive increase in output. It follows that there cannot occur (payoff relevant) ties at the margin among dispatched units, unless the equilibrium is competitive. In contrast, ties at the equilibrium price with only one firm dispatching output at the margin will be (almost always) the rule. This will be clearly the case with inelastic demand, as the price setter will optimally drive the price up to the next step in its rivals' bid functions. ${ }^{21}$

An important consequence of Proposition 2 is that at any non competitive Nash equilibrium, there is a unique price setter. This fact allows us to proceed by fixing the identity of the price setter and treating all other firms as non price setters.

\subsection{The non price setters' and the price setter's optimal behavior}

In order to derive the necessary and sufficient conditions for equilibrium bidding, we will first characterize firms' optimal bidding behavior conditional on their identities.

\footnotetext{
${ }^{19}$ The analysis of the irregular cases can be found at the Journal's Web Site as supplementary material.

${ }^{20}$ Without supply rationing at $p^{c}$, there could exist equilibria with $p^{*}>p^{c}$ and ties at the margin, as long as firms still produce their competitive quantities. One simple example in which this is the case has $D \quad 2, c_{1} \quad c_{2} \quad\{(0,1)\}$ and $c_{3} \quad\{(c, 1)\}$. In equilibrium, $p^{*} \quad c>0 \quad p^{c}$ while $q_{n}^{*} \quad q_{n}^{c} \quad 1$ for $n \quad 1,2$, and $q_{3}^{*} \quad q_{3}^{c} \quad 0$. Both firms 1 and 2 could be price-setters if they bid at $b_{1} \quad b_{2} \quad\{(c, 1)\}$, but the same outcome would also arise with just one of them bidding at $c$ while the other bids below. In this sense, if there is no supply rationing at $p^{c}$, ties at the margin among dispatched units can occur in equilibrium, but such ties are payoff irrelevant.

21 With a rationing pro-rata on-the-margin rule, such a tie at the margin would not arise. Nevertheless, the outcome would (almost perfectly) approximate the equilibrium outcome under the efficient tie-breaking rule. Note that if the tie-breaking rule did not allocate the marginal output to the low cost firm first, such a firm would avoid the tie by bidding slightly below its rivals' first non-accepted bid.
} 
By Proposition 1, we already know that the non price setters behave as price takers, i.e., they have to decide how much to produce at a given market price, $p^{*}$. Formally,

$$
q_{j}^{N P S}\left(p^{*}\right) \in \arg \max _{q_{j}^{*}} \pi_{j}^{N P S}\left(p^{*} ; q_{j}^{*}\right),
$$

where

$$
\pi_{j}^{N P S}\left(p^{*} ; q_{j}^{*}\right)=p^{*}\left[\begin{array}{lll}
q_{j}^{*} & x_{j}
\end{array}\right] C_{j}\left(q_{j}^{*}\right)+\tau_{j} x_{j} .
$$

In order to produce $q_{j}^{N P S}\left(p^{*}\right)$, the non price setters can bid at marginal costs or use any other outcome equivalent strategy. However, their choice of bidding strategies is not irrelevant, as these determine the shape of the residual demand faced by the price setter and hence its optimal bidding behavior. For this reason, we will not assume that the non price setters bid at marginal costs, unless we make it explicit. It follows that we can readily compute the price setter's production in equilibrium, but not outside the equilibrium. In particular, at any candidate equilibrium with $p^{*}=p^{c}$, the price setter produces $q_{i}^{c}$, while if $p^{*}>p^{c}$, given that the market must clear, the price setter produces

$$
q_{i}^{P S}\left(p^{*}\right)=D\left(p^{*}\right) \sum_{j \neq i} q_{j}^{N P S}\left(p^{*}\right)
$$

The above equation might not be satisfied at prices other than the equilibrium price, given that the non price setters need not be bidding at marginal costs outside the equilibrium, and given that the market need not always clear.

Instead of choosing how much to produce at a given price, the price setter behaves as if it were to choose the market price that maximizes its profits over its residual demand, i.e., total demand minus the quantity that the non price setters are willing to supply at each price. Formally,

$$
p_{i}^{P S}\left(b_{-i}\right) \in \arg \max _{p^{*}} \pi_{i}^{P S}\left(p^{*} ; b_{-i}\right),
$$

where

$$
\pi_{i}^{P S}\left(p^{*} ; b_{-i}\right)=p\left[q_{i}^{*}\left(p^{*} ; b_{-i}\right) \quad x_{i}\right] \quad C\left(q_{i}^{*}\left(p^{*} ; b_{-i}\right)\right)+\tau_{i} x_{i}
$$

and

$$
q_{i}^{*}\left(p^{*} ; b_{-i}\right)=\max \left\{0, D\left(p^{*}\right) \sum_{j \neq i} q_{j}^{*}\left(p^{*} ; b_{-j}\right)\right\} .
$$

In order to understand the price setter's bidding incentives, consider the change in firm i's profits when it raises the market price from $p^{*}$ to some $p^{\prime}>p^{*}$,

$$
\pi_{i}^{P S}\left(p^{\prime} ; b_{-i}\right) \quad \pi_{i}^{P S}\left(p^{*} ; b_{-i}\right)=\left[\begin{array}{lll}
p^{\prime} & p^{*}
\end{array}\right]\left[\begin{array}{ll}
q_{i}^{*}\left(p^{\prime} ; b_{-i}\right) & x_{i}
\end{array}\right] \quad \int_{q_{i}^{*}\left(p^{\prime} ; b_{i}\right)}^{q_{i}^{*}\left(p^{*} ; b_{i}\right)}\left[\begin{array}{ll}
p^{*} & c_{i}(z)
\end{array}\right] d z .
$$

As in any standard monopoly problem, a price increase implies greater revenues through the firm's net position the first term in (4) but it also implies a profit loss due to the output reduction the second term in (4). Accordingly, the price setter's incentives to raise the price are stronger the bigger its net position is, the less elastic its residual demand is, and the smaller the price cost margin on its lost production is. It then follows that firm $i$ 's profit maximizing price given its rivals' strategies, $p_{i}^{P S}\left(b_{-i}\right)$, is non increasing in its contract cover, $x_{i}$. This mimics the standard result that smaller firms (here, firms with smaller net positions) have weaker incentives to raise prices.

We conclude this subsection by comparing the price setter's and non price setters' profits. To simplify notation, we write $\pi_{i}^{P S}\left(p^{*}\right)$ and $\pi_{j}^{N P S}\left(p^{*}\right)$, for $j \neq i$, to respectively denote the price setter's and non price setters' profits when the former sets the market price at $p^{*}$ and all the latter produces $q_{j}^{N P S}\left(p^{*}\right)$.

Lemma 4. Let $x_{n}<q_{n}^{c}$ hold for all firms. For any market price $p^{*}$, (i) the non price setters' profits $\pi_{j}^{N P S}\left(p^{*}\right)$ are increasing in $p^{*}$, and (ii) they weakly exceed those they would get as a price setter at the same market price, $\pi_{i}^{P S}\left(p^{*}\right) \leq \pi_{i}^{N P S}\left(p^{*}\right)$.

Since under the regular cases all firms are net sellers in equilibrium, any price increase makes the non price setters strictly better off. We will thus assume that whenever the price setter is indifferent between multiple prices, it always chooses the highest one, as it is the payoff dominant one. Finally, the profits that a firm earns as a non price setter are bounded below by the profits it could obtain as a price setter: both the non price setters and the price setter are paid the same price, but the price setter sells (weakly) less and thus gives up a positive profit margin on its reduced production.

\subsection{Equilibrium characterization}

An equilibrium outcome is a collection of quantities produced by the non price setters and a price chosen by the price setter such that no firm wants to deviate, either by changing its quantity or price choice, or by changing its identity. The following theorem provides necessary and sufficient conditions for equilibrium bidding in the regular cases. 
Theorem 1. Let $x_{n}<q_{n}^{c}$ hold for all firms. A strategy profile $b$ constitutes a Nash equilibrium in which firm $i$ is the price setter if and only if the following three conditions hold

(1) $p^{*}=p_{i}^{P S}\left(b_{-i}\right) \geq p^{c}$ and $q_{j}^{*}=q_{j}^{N P S}\left(p^{*}\right)$ for all $j \neq i$.

(2) $\pi_{i}^{P S}\left(p^{*}\right) \geq \pi_{i}^{N P S}(p)$ for all $p<p^{*}$ such that $q_{i}^{N P S}(p)+\sum_{j \neq i} q_{j}(p ; b)=D(p)$.

(3) $\pi_{j}^{N P S}\left(p^{*}\right) \geq \pi_{j}^{P S}\left(p_{j}^{P S}\right)$ for all $j \neq i$ such that $p_{j}^{P S}\left(b_{-j}\right)>p^{*}$.

In equilibrium, the price setter chooses the price that maximizes its profits over the residual demand, $p^{*}=p_{i}^{P S}\left(b_{-i}\right)$. By weak dominance arguments, it must be either equal or above the competitive price. All the other firms must behave as price takers given $p^{*}$, and hence produce the same as if they were bidding at marginal costs (Proposition 1).

By condition (1) of Theorem 1 above, all firms are already optimizing conditionally on their identities. Thus, the only relevant deviations are those by which firms reverse their identities. Since the price setter might consider becoming a non price setter in order to sell more at a lower market price, condition (2) is needed to rule out such deviations. In turn, since all the non price setters are net sellers in equilibrium, those with profit maximizing prices no larger than $p^{*}$ never find it optimal to deviate: not only they would sell their production at a (weakly) lower price, but also they would also sell less. Hence, the only relevant deviations are those by the remaining non price setters, but condition (3) rules them out.

\subsection{Equilibrium existence and multiplicity}

For a given price setter, there exist multiple bid function profiles that constitute an equilibrium (all those satisfying Theorem 1). This derives from the fact that firms only care about one point in their bid functions, the one corresponding to the market price. Furthermore, the multiplicity of equilibrium bid functions may pave the way for multiplicity of equilibrium outcomes to emerge. Fortunately, this is not the case, as stated next. ${ }^{22}$

Proposition 3. ( $i$ ) There exists an equilibrium in which firm $i$ is the price setter if and only if the equilibrium in which firm $i$ sets the price at $p^{*}=p_{i}^{P S}\left(c_{-i}\right)$ while all the other firms bid at marginal costs exists. (ii) Furthermore, if there also exist other equilibria in which firm $i$ is the price setter, the one above is the payoff dominant one.

Proposition 3 implies that, conditionally on the identity of the price setter, there is no loss of generality (as far as equilibrium outcomes are concerned) in restricting attention to equilibria in which the non price setters bid at marginal costs and the price setter maximizes its profits over the resulting residual demand. This claim is supported by two facts: if such an equilibrium does not exist, there does not exist any other equilibrium in which the same firm acts as the price setter; while if it exists, it is either the unique equilibrium or the payoff dominant one.

The next result, which is a corollary of Theorem 1, guarantees equilibrium existence. In particular, the candidate equilibrium with the highest price always exists.

Corollary 1. The equilibrium with $p^{*}=\max _{i} p_{i}^{P S}\left(c_{-i}\right)$ always exists.

We have shown that, conditionally on the identity of the price setter, equilibrium multiplicity is outcome irrelevant. However, the multiplicity of equilibria that differ in the identity of the price setter might potentially result in different equilibrium prices. This multiplicity was highlighted in the illustrative example provided in Section 3 but it holds more generally. Furthermore, existence of a candidate equilibrium implies that all other candidate equilibria with higher equilibrium prices also exist. To understand this, note that the profits that a firm achieves as a price setter are given, but the profits it makes as a non price setter are increasing in the equilibrium price (Lemma 4). Hence, if none of the firms has incentives to deviate from a candidate equilibrium, it must also be the case that none of them wants to deviate from a candidate equilibrium with a higher price. For similar reasons, if a candidate equilibrium does not exist, there does not exist any other candidate equilibrium with a lower price. These results are stated in the last corollary of Theorem 1.

Corollary 2. If the equilibrium with $p^{*}=p_{i}^{P S}\left(c_{-i}\right)$ exists, the equilibria with $p^{*}=p_{n}^{P S}\left(c_{-n}\right) \geq p_{i}^{P S}\left(c_{-i}\right)$ also exist. Alternatively, if it does not exist, the equilibria with $p^{*}=p_{n}^{P S}\left(c_{-n}\right) \leq p_{i}^{P S}\left(c_{-i}\right)$ do not exist either, $n=1, \ldots, N$.

Combining the two corollaries above, it follows that under the same primitives of the game, a competitive equilibrium cannot coexist with a non competitive equilibrium.

\subsection{The impact of forward contracts}

We are now ready to analyze the impact of forward contract commitments on equilibrium outcomes. Since our aim is to perform comparative statics with respect to changes in contracts, in what follows, with some abuse of notation, we will write $p_{i}^{P S}\left(x_{i}\right)$ to denote the profit maximizing price of firm $i$ when its rivals bid at marginal costs and its contract obligation

\footnotetext{
22 In contrast, multiplicity of equilibrium outcomes is pervasive in auctions with continuous bid functions (see Wilson, 1979; Klemperer and Meyer, 1989; Back and Zender, 1993, among others). Note that having net-sellers is crucial for the result, as in the irregular cases multiple equilibrium outcomes might arise (see the analysis in the supplementary material).
} 
is $x_{i}$. We will also index firms according to their profit maximizing prices at the no contracts case, i.e., $p_{1}^{P S}(0) \geq$ $p_{2}^{P S}(0) \geq \cdots \geq p_{N}^{P S}(0)$.

Suppose first that firms are symmetric in all respects. The next lemma characterizes the impact on prices and productive efficiency of increasing total contracts when they are either symmetrically or asymmetrically distributed among firms.

Lemma 5. In a symmetric oligopoly,

(i) If forward contracts are equally distributed among firms, i.e., $x_{1}=\cdots=x_{N}=x<q^{c}$, equilibrium prices are non increasing in $x$ and productive efficiency is non decreasing in $x$.

(ii) If forward contracts are not equally distributed among firms, the highest equilibrium price is (weakly) higher and the associated productive efficiency is (weakly) lower than under the equal contract distribution.

(iii) The highest equilibrium price with contracts is (weakly) lower and the associated productive efficiency is (weakly) higher than under the no contract case. The comparison is strict if contracts are allocated to all firms.

Since firms are fully symmetric, there exist $N$ price equivalent equilibrium outcomes that only differ in the identity of the price setter. As firms' contract cover is increased, the equilibrium price is reduced and productive efficiency is improved. ${ }^{23}$ Furthermore, any departure from the symmetric contract distribution would weaken the positive effect of contracts as firms' ex ante symmetry, which induces more competitive outcomes, would no longer be preserved. ${ }^{24}$ However, the highest equilibrium price is (weakly) lower with contracts than without, regardless of how contracts are distributed. If contracts are allocated to all firms but at least one, the equilibrium price without contracts remains to be the highest equilibrium price. However, if contracts are allocated to all firms, all their profit maximizing prices go down, and so does the highest equilibrium price.

We next allow for all types of asymmetries among firms, and perform comparative statics with respect to contract volume up to firms' competitive quantities, depending on the distribution of contracts across firms.

Proposition 4. Consider an asymmetric oligopoly, such that at the no contracts case equilibrium prices are $\left\{p_{1}^{P S}(0), \ldots, p_{i}^{P S}(0)\right\}$ for $1 \leq i \leq N$, while prices $p_{n}^{P S}(0)$ for $i<n \leq N$ cannot be sustained because firm 1 would deviate from the candidate equilibrium at which firm $n$ is price setter.

(i) If forward contracts are awarded to firm 1 only, prices are (weakly) lower than at the no contracts case. Furthermore, a (weak) non monotonic relationship between contract volume and equilibrium prices may arise.

(ii) If forward contracts are awarded to firm i only, there exists $x_{i}^{\prime} \in\left(0, q_{i}^{c}\right)$, such that any contract allocation $x_{i}<x_{i}^{\prime}$ leads to (weakly) lower prices than at the no contracts case, whereas any contract allocation $x_{i} \geq x_{i}^{\prime}$ leads to (weakly) higher prices. Hence, there is a (weak) non monotonic relationship between contract volume and equilibrium prices.

(iii) If forward contracts are awarded to firms $n>i$ only, they have no effect on equilibrium outcomes.

At the no contracts case, firm 1 and firm $i$ set the highest and lowest equilibrium prices respectively, while firms $n>i$ behave as price takers at any equilibrium. Accordingly, we say that firm 1 and firm $i$ have 'high' and 'low' market power respectively, while firms $n>i$ have 'no' market power at all. The impact of forward contracts on equilibrium prices depends on how contracts are awarded among these firms.

To understand the results in Proposition 4 above, it is important to first recall that as a firm's contracts go up, its profit maximizing price (weakly) goes down. In turn, given that a low price makes it relatively more attractive for an uncontracted non price setter to become the price setter, the equilibrium in which the contracted firm sets the price might disappear. By the opposite logic, the contracted firm now finds it more appealing to be the non price setter, so that if no other firm has incentives to deviate, there can now appear new equilibria involving lower prices. These effects are illustrated in Figs. 35.

If all contracts are awarded to the firm with 'high' market power, as in part (i), contracts (weakly) reduce prices with respect to the no contracts case. This holds true regardless of whether the equilibrium in which the contracted firms sets the price disappears (Fig. 3), and regardless of whether new equilibria arise (Fig. 5), given that in any case the remaining equilibria result in lower prices.

The above conclusion may be reversed when all contracts are awarded to the firm with 'low' market power, as in part (ii). In this case, it is still true that contracts (weakly) reduce prices when the firm with 'low' market power sets the price. However, prices might go up when such equilibrium disappears (for $x_{i} \geq x_{i}^{\prime}$ ). Given that the equilibrium price will then be set

\footnotetext{
${ }^{23}$ In contrast, if total contract volume was further increased (taking us away from the regular cases), firms would start exercising monopsony power, leading to prices below the competitive price. Furthermore, since the price-setter would produce more than at the competitive outcome, productive inefficiencies might emerge.

${ }^{24}$ For given contracts, similar results also arise in Allaz and Vila' (1993) and Bushnell' (2007) Cournot models, as well as in Newbery (1998) Supply Function Equilibrium model.
} 


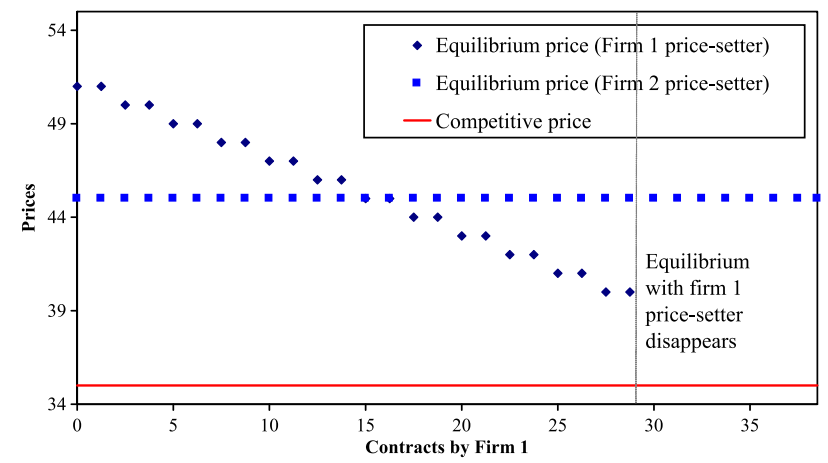

Fig. 3. Forward contracts by firm 1 and equilibrium prices (asymmetric firms (55\%, 45\%)).

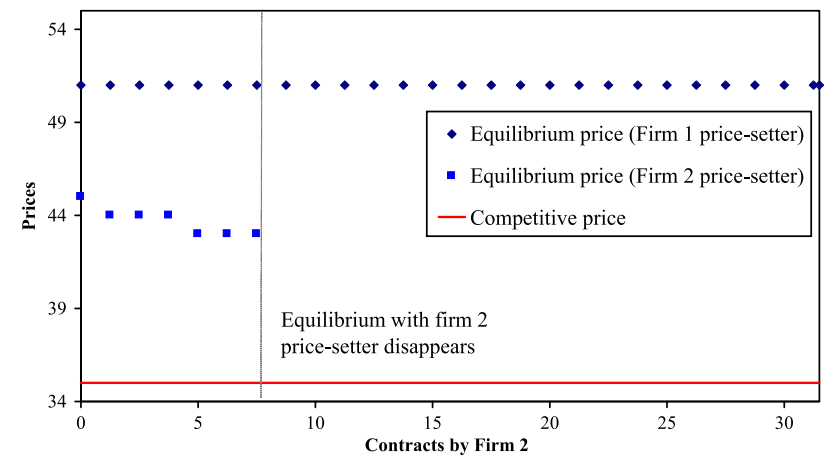

Fig. 4. Forward contracts by firm 2 and equilibrium prices (asymmetric firms (55\%, 45\%)). Note: In Figs. 2 and 3 we have assumed $N \quad 2$. There are 200 units, two at each marginal cost level, $k \quad 1, \ldots, 100$, each owned by a different firm. Firm 1's units have capacity 1.10 while firm 2 's units have capacity 0.9. Demand is price-inelastic, $D \quad 70$, so that $p^{c} \quad 35$ and $q_{1}^{c} \quad 38.5>q_{2}^{c} \quad 31.5$.

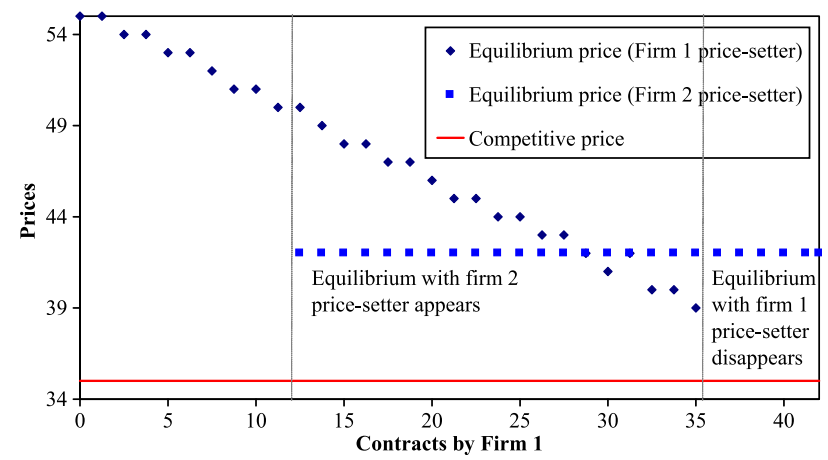

Fig. 5. Forward contracts by firm 1 and equilibrium prices (asymmetric firms (60\%, 40\%)). Note: In Fig. 4 we have assumed $N \quad 2$. There are 200 units, two at each marginal cost level, $k \quad 1, \ldots, 100$, each owned by a different firm. Firm 1's units have capacity 1.20 while firm 2's units have capacity 0.8 . Demand is price-inelastic, $D \quad 70$, so that $p^{c} \quad 35$ and $q_{1}^{c} \quad 42>q_{2}^{c} \quad 28$.

by firms with higher profit maximizing prices, contracts in this case may result in (weakly) higher prices as compared to the no contracts case (Fig. 4). To the extent that higher spot market prices translate into higher forward contract prices, this effect would make both spot market customers as well as forward contract holders worse off.

Last, if contracts are awarded to firms with 'no market power', as in part (iii), contracts simply have no effect as such firms behave as price takers with or without contracts.

In order to highlight the distinct impact of contracts depending on how these are distributed, Proposition 4 has considered the case in which all contracts are allocated to a single firm. Allocating contracts to different firms at the same time would reinforce the pro competitive effects identified above. For instance, allocating a given amount of contracts to firm 2 is more effective when firm 1 also holds contracts. This is because the critical value $x_{2}^{\prime}$ goes up, thus enlarging the set of parameter values for which low and high price equilibria coexist and reducing the incidence of anti competitive effects.

The effect of forward contracts on prices depends on several factors, including firms' cost functions, firms' sizes and, in general, the degree of firms' asymmetries. Large asymmetries, such that only one firm has market power at the 
no contracts case, lead to a clear cut policy conclusion: the dominant firm should be forced to hold contracts; getting contract volume wrong in this case is not very costly, as contracts would in any case be effective. In contrast, mild asymmetries among firms (particularly so, between the firms with 'high' and 'low' market power) might give rise to the anti competitive effects identified in Proposition 4.

To illustrate this point, consider the following particular case of the general model. There are two firms with capacities $K_{1}=\alpha K>K_{2}=(1 \alpha) K$, where $\alpha$ provides a measure of firms' capacity asymmetries. All production units have equal marginal costs normalized to zero; competitive quantities are thus $q_{1}^{c}=\alpha D(0)$ and $q_{2}^{c}=(1 \alpha) D(0)$. Demand $D(p)$ is assumed to be downward sloping, and firms' profits are assumed concave. To make the problem interesting, assume that aggregate capacity is enough to satisfy all demand at marginal costs, i.e., $D(0)<K$, and that if firms' capacities were symmetric, none of them would have enough capacity to satisfy all demand alone, i.e., $K / 2<D(0)<K$.

Under this specification, the following lemma holds:

Lemma 6. Suppose contracts $x_{2} \in\left(0, q_{2}^{c}\right)$ are allocated to firm 2. There exists $\widehat{\alpha}\left(x_{2}\right)$ such that equilibrium prices are $\left\{p_{1}^{P S}(0), p_{2}^{P S}\left(x_{2}\right)\right\}$ if $\alpha<\widehat{\alpha}\left(x_{2}\right)$ and $\left\{p_{1}^{P S}(0)\right\}$ if $\alpha \in\left[\widehat{\alpha}\left(x_{2}\right), 1\right]$. The critical value $\widehat{\alpha}\left(x_{2}\right)$ is decreasing in $x_{2}$; in particular, $\widehat{\alpha}\left(x_{2}\right)<\widehat{\alpha}(0)$; while the price difference $p_{1}^{P S}(0) \quad p_{2}^{P S}\left(x_{2}\right)>0$ is increasing in $\alpha$ and $x_{2}$.

Lemma 6 above implies that allocating contracts to firm 2 is inconsequential in markets with large asymmetries, i.e., for $\alpha>\widehat{\alpha}(0)$, as firm 2 is a non price setter with or without contracts. In markets with small asymmetries, i.e., for $\alpha<\widehat{\alpha}\left(x_{2}\right)$, allocating contracts $x_{2}$ to firm 2 is pro competitive, as one of the two possible equilibrium prices goes down. In contrast, when asymmetries between firms 1 and 2 are neither too large nor too small, i.e., for $\alpha \in\left(\widehat{\alpha}\left(x_{2}\right), \widehat{\alpha}(0)\right)$, allocating contracts $x_{2}$ is anti competitive as the low price equilibrium disappears. Furthermore, it is precisely when contracts rule out the low price equilibrium when the difference between the high price, $p_{1}^{P S}(0)$, and the low price, $p_{2}^{P S}\left(x_{2}\right)$, is wider.

As a conclusion, the regulator should be most cautious when deciding on contract volume and its distribution among firms in markets in which firms' asymmetries are neither too large nor too small. However, it is also in these cases when contracts can potentially play a more crucial role, as encouraging firms with 'medium' and 'low' market power to purchase such contracts may counterbalance the market power of the dominant firms.

\section{Simulating the impact of forward contracts}

We next apply the theoretical model to simulate equilibrium bidding behavior and market outcomes in the Spanish electricity market during 2005. The aim is to illustrate with real data the strategic effects of contracts that we have described in Section $4 .^{25}$

We have considered alternative scenarios regarding total contract volume and its distribution across firms. In particular, focusing on the equilibria in which only the two main firms (Endesa and Iberdrola) are price setters, ${ }^{26}$ we have computed both the competitive as well as the equilibrium market outcomes under the no contracts case and the cases in which either Endesa (END) or Iberdrola (IB) hold contracts, ranging from 1 to $8 \mathrm{GWs.} \mathrm{To} \mathrm{have} \mathrm{an} \mathrm{idea} \mathrm{of} \mathrm{what} \mathrm{this}$ range of contract cover meant for firms over their total capacity, let us note that Endesa's and Iberdrola's total capacity in 2005 was almost 11 GWs and 8.5 GWs, respectively.

Table 2 reports the markups that result from comparing the simulated equilibrium price to the price that would arise in a competitive market (as suggested in Borenstein et al., 2002). Markups are computed at four demand levels (expressed in percentiles), under the no contracts case and under the cases in which Endesa has contracted either 2 or 5 GWs, and Iberdrola has contracted either 6 or 8 GWs (results for all other cases are qualitatively similar). By comparing the markups across firms at the no contracts case (first two columns in Table 2), we can readily verify that Endesa's profit maximizing price exceeds that of Iberdrola's for all demand levels considered, except for peak load, at which both profit maximizing prices coincide.

Let us first consider the effects of contracts when awarded to the firm with the high profit maximizing price, Endesa. First, contracts may reduce Endesa's profit maximizing price as a price setter; this is, for instance, the case when Endesa contracts 2 GWs and demand is at its $75 \%$ or $50 \%$ percentile. Second, contracts may give rise to a new equilibrium in which Iberdrola sets a lower price; this is the case when Endesa contracts either 2 or 5 GWs and demand is at its $50 \%$ percentile. Last, contracts may eliminate certain equilibria at which Endesa sets the price; this is the case when Endesa contracts 5 GWs for all demand levels. Therefore, contracts by Endesa have (weak) pro competitive effects.

However, such a conclusion is reversed when contracts are awarded to the firm with the low profit maximizing price, Iberdrola. More specifically, contracts by Iberdrola have (weak) anti competitive effects when they destroy low price equilibria. This is the case when Iberdrola contracts either 6 or $8 \mathrm{GWs}$ and demand is at its $75 \%$ percentile.

\footnotetext{
${ }^{25}$ The Journal's Web site contains supplementary material with details on the Spanish electricity market as well as on the procedures we have followed to compute firms' marginal costs.

${ }^{26}$ Since the simulations are conducted on an hourly basis over a year, there are at least 8760 and at most (if both firms act as price-setters) 17,520 equilibrium market outcomes under each of the 17 cases considered, plus the 8760 competitive outcomes (these are the same regardless of whether firms hold contracts or not)_adding up to over 300,000 simulated market outcomes in total. Simulations have been produced by ENERGEIA, a simulation software developed by the authors.
} 
Table 2

The impact of forward contracts on markups $\left(p^{*}-p^{c}\right) / p^{*}$ expressed in percentage points in the Spanish electricity market during 2005.

\begin{tabular}{|c|c|c|c|c|c|c|c|c|c|c|}
\hline \multirow[t]{2}{*}{ \% Price-setter } & \multicolumn{2}{|c|}{ No contracts } & \multicolumn{2}{|c|}{ END 2 GWs } & \multicolumn{2}{|c|}{ END 5 GWs } & \multicolumn{2}{|c|}{ IB 6 GWs } & \multicolumn{2}{|c|}{ IB 8 GWs } \\
\hline & IB & END & IB & END & IB & END & IB & END & IB & END \\
\hline Peak load & 50.0 & 50.0 & 50.0 & 50.0 & 50.0 & $*_{-}$ & 50.0 & 50.0 & $*_{-}$ & 50.0 \\
\hline 75 & 11.2 & 15.0 & 11.2 & $* 11.6$ & 11.2 & $*_{-}$ & $*_{-}$ & 15.0 & $*_{-}$ & 15.0 \\
\hline 50 & - & 15.9 & $* 5.2$ & *10.7 & $* 5.2$ & $*_{-}$ & - & 15.9 & - & 15.9 \\
\hline 25 & 23.4 & 23.6 & 23.4 & 23.6 & 23.4 & $*_{-}$ & 23.4 & 23.6 & 23.4 & 23.6 \\
\hline
\end{tabular}

The table reports the simulated mark-ups $\left(p^{*}-p^{c}\right) / p^{*}$ for four demand levels (the year's peak load, and the $75 \%, 50 \%$ and $25 \%$ demand percentiles). The results are divided in columns, depending on the identity of the price-setter. A table entry is left empty if, for the associated demand level and contract volumes, there is not an equilibrium in which such a firm behaves as price-setter. An asterisk denotes that the equilibrium has changed with respect to the no-contracts case.

Table 3

The impact of forward contracts on total payments to producers (Million $€$ ) for the Spanish electricity market during 2005.

\begin{tabular}{|c|c|c|}
\hline & \multicolumn{2}{|c|}{$\Delta$ Payments } \\
\hline & Min & Max \\
\hline \multicolumn{3}{|c|}{ Contracts by ENDESA (GWs) } \\
\hline 1 & -84 & -107 \\
\hline 2 & -143 & -194 \\
\hline 3 & -377 & -410 \\
\hline 4 & -457 & -577 \\
\hline 5 & -439 & -608 \\
\hline 6 & -456 & -632 \\
\hline 7 & -548 & -639 \\
\hline \multirow[t]{3}{*}{8} & -709 & -654 \\
\hline & \multicolumn{2}{|c|}{$\Delta$ Payments } \\
\hline & Min & Max \\
\hline \multicolumn{3}{|c|}{ Contracts by IBERDROLA (GWs) } \\
\hline 1 & -24 & -78 \\
\hline 2 & -54 & -161 \\
\hline 3 & -88 & -222 \\
\hline 4 & -117 & -280 \\
\hline 5 & -181 & -379 \\
\hline 6 & -200 & -434 \\
\hline 7 & -169 & -437 \\
\hline 8 & -171 & -437 \\
\hline
\end{tabular}

Total payments to producers under the competitive outcome are $9599 \mathrm{M} €$; the minimum value under the no-contracts case is $11,422 \mathrm{M} €$, while the maximum is $11,728 \mathrm{M} €$. The table reports how these figures change when forward contracts are introduced. Given that there might be multiplicity of equilibrium outcomes, the Min and the Max columns report the minimum and maximum change in total payments.

The effects of contracts reported so far vary with the demand level. For example, whereas at very high or very low demand levels contracts barely have any effect on equilibrium outcomes, their effect for intermediate demand levels can go in either direction depending on contract volume and contract allocation. In real markets, since demand changes over time while contract volumes remain fixed, the overall effect of contracts will depend on the relative occurrence of periods in which contracts are either pro competitive or anti competitive. For illustrative purposes, we have assessed the effect that contracts would have had on the Spanish electricity prices during 2005 by computing total payments to producers over the year.

Table 3 reports the change in total payments (spot market price times each firm's total output) when contracts are introduced. Given equilibrium multiplicity, the table reports the minimum and the maximum change in payments. Under all contract cases, total payments to generators go down, thereby indicating that the pro competitive effects of contracts dominate over the anti competitive ones. However, the latter can also be inferred from these figures as they account for the non monotonic relationship between payments to producers and total contract volume. For instance, such non monotonicity arises when Iberdrola's contracts are increased above $6 \mathrm{GWs}$, when savings are reduced from $200 \mathrm{M} €$ to either $169 \mathrm{M} €$ or $171 \mathrm{M} €$. 


\section{Conclusions}

In this paper we have analyzed the impact of forward contract obligations on the performance of spot markets in a model that tries to capture the essential institutional and structural features of electricity markets. Instead of assuming either Cournot or Bertrand competition, we have tried to model the actual market rules that govern most electricity markets in practice. In particular, we have assumed that firms compete by submitting discrete supply functions. Furthermore, we have put no restrictions on the market demand function which could be either downward sloping or price inelastic, or the firms'cost functions which could result in either constant or step wise increasing marginal costs, and could be symmetric or asymmetric across firms. Thus, the model is flexible enough so as to make it comparable with other more stylized models, at the same time as it allows for all degrees of complexity. Indeed, we have used it to simulate real electricity market outcomes in order to provide an order of magnitude for the model predictions.

We find that forward contracts play a key role in shaping equilibrium market outcomes. If contracts are awarded to dominant firms, they may destroy the equilibria at which such firms set prices. Since the surviving equilibria involve lower prices, forward contracts are unambiguously pro competitive. However, the contrary occurs if contracts are awarded to firms with weak but yet some market power. In particular, contracts might destroy the low price equilibria, and hence have anti competitive effects. The effects of contracts on equilibrium existence also suggest that more is not always better. That is, if an increase in contract volume destroys the equilibrium at which the contracted firm sets the price, more contracts might lead to higher prices.

From a policy perspective, our analysis thus implies that forward contracts should be awarded in ways that align all firms' interests by (virtually) reducing their asymmetries. Paradoxical though it may seem, it is as important to mitigate the large firms' incentives to increase prices as it is to enhance those of smaller competitors. This could be achieved by encouraging the medium to small firms in the industry to act as counterparts of the forward contract commitments imposed on the dominant producers. Similarly, restricting certain firms from entering into these contracts can be misplaced. Regarding contract volume, forcing firms to hold too few or too many forward contracts might be at best ineffective. Since the optimal contract volume ultimately depends on firms' cost structures and demand, it should be determined on a case by case basis.

To conclude, even though our analysis has been inspired by the workings of electricity markets, we believe that its implications have broader applicability. Since the most relevant features of our model are not unique to electricity markets, similar analyses could be applied to other contexts. Indeed, there are several other markets in which forward contracts and auctions coexist (e.g. treasury markets, gas markets, etc.), or markets which are organized in ways that make auction theory useful for understanding firms' strategic behavior (Klemperer, 2003).

\section{Acknowledgments}

We are grateful to Antonio Cabrales, Álvaro Cartea, Jim Bushnell, Alberto de Frutos, Giulio Federico, José Luis Ferreira, Mónica Gandolfi, Ángel Hernando, Xavier Jarque, Kai Uwe Kühn, Juan Toro, Achim Wambach, two anonymous referees, and seminar audiences at the UCEI (Berkeley), Universidad de Málaga, Universidad Carlos III de Madrid, IESE (Barcelona), EARIE Conference (Toulouse), ASSET Meeting (Florence), Universidad Complutense (Madrid), the CEPR Conference on Applied IO (Manheim), IFN (Stockholm) and HEREC (Helsinki). Pablo Angulo provided excellent research assistance. Both authors acknowledge Fundación Ramón Areces for financial support; the first and second authors also acknowledge financial support awarded by the Spanish Ministry of Education and Science, Project SEJ2007 67436, and the Spanish Ministry of Science and Innovation, Project 2010/02481/001, respectively.

\section{Appendix A. Proofs}

In this appendix we provide proofs of all results in the paper, except for Lemmas 1 and 5 , and Corollaries 1 and 2 . The proofs of these results can be found at the Journal's Web site as supplementary material.

Notation: The following pieces of notation are used throughout the appendix. We will denote by $\underline{q}_{n}(p)$ the maximum quantity that firm $n$ can produce at marginal costs strictly below $p$, and by $\bar{q}_{n}(p)$ the maximum quantity that firm $n$ can produce at marginal costs not exceeding $p$. Since the marginal cost curve, $c_{n}(q)$, is a left continuous non decreasing step function, by treating all production units with equal marginal costs as the same unit we can write it as a finite number of cost quantity pairs, $c_{n}=\left\{\left(c_{n s}, q_{n s}\right)_{s}^{\tilde{s}_{n}}{ }_{1}\right\}$ with $c_{n s+1}>c_{n s}, q_{n s+1}>q_{n s}$ and $q_{n \tilde{s}_{n}}=K_{n}$. Since $\underline{q}_{n}(p)$ and $\bar{q}_{n}(p)$ are on the corners of firm $n$ 's marginal cost function, the following properties trivially follow:

(i) $\underline{q}_{n}(p)$ and $\bar{q}_{n}(p)$ are non decreasing in $p$.

(ii) $\underline{q}_{n}^{n}(p)=\bar{q}_{n}(p)=q_{n s}$ for all $p \in\left(c_{n s}, c_{n s+1}\right]$.

(iii) $\underline{q}_{n}(p)=q_{n s-1}<\bar{q}_{n}(p)=q_{n s}$ for $p=c_{n s}$.

(iv) $\underline{q}_{n}\left(p^{\prime}\right) \geq \bar{q}_{n}(p)$ for all $p^{\prime}>p$. 


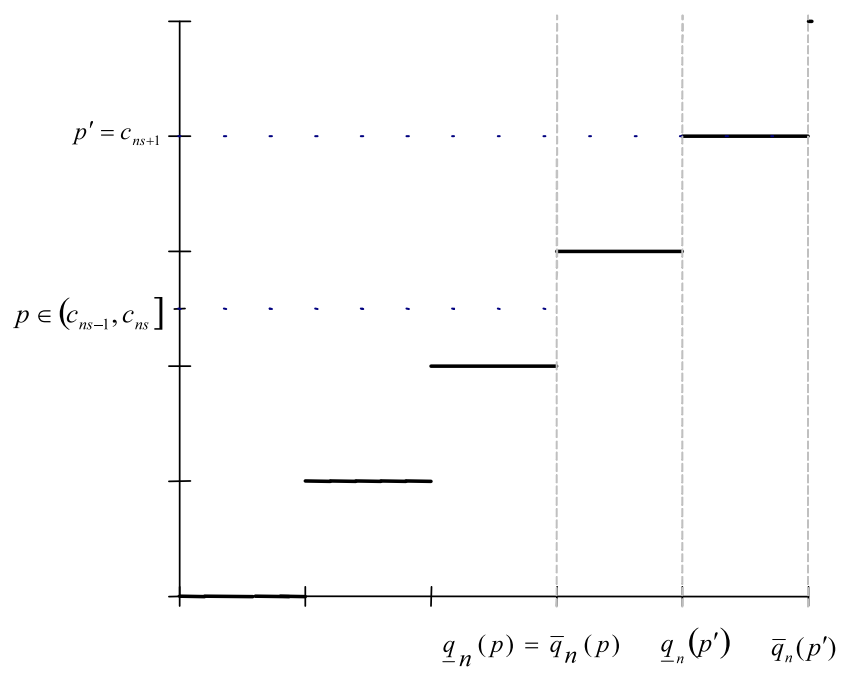

Fig. 6. An example of a firm's marginal cost function and the quantities $\underline{q}_{n}(p)$ and $\bar{q}_{n}(p)$.

The maximum quantities that a firm can produce either below or at marginal costs are non decreasing in $p$, (i). If $p$ does not intersect the firm's marginal cost function (or equivalently, if it falls on a vertical segment), then $\underline{q}_{n}(p)$ and $\bar{q}_{n}(p)$ are equal, (ii). Otherwise, $q_{n}(p)<\bar{q}_{n}(p)$, with $p$ reflecting the marginal costs at which the firm produces the quantities in $\left(q_{n s-1}, q_{n s}\right.$ ], (iii). Last, $\underline{q}_{n}\left(p^{\prime}\right)$ exceeds $\bar{q}_{n}(p)$ whenever there is a step in firm $n^{\prime}$ s marginal cost function in between $p^{\prime}$ and $p$, and they are both equal otherwise, (iv). These results are illustrated in Fig. 6.

Proof of Lemma 3. To show $q_{j}^{*} \leq \bar{q}_{j}\left(p^{*}\right)$ for all $j \neq i$, assume for the sake of contradiction that there is some firm $j$ for which $q_{j}^{*}>\bar{q}_{j}\left(p^{*}\right)$ holds in equilibrium. By weak dominance arguments, it must be the case that $q_{j}^{*} \leq x_{j}$ as it could not otherwise bid below marginal costs to dispatch $q_{j}^{*}>\bar{q}_{j}\left(p^{*}\right)$. It hence follows that $q_{j}^{*}>x_{j}$ suffices for $q_{j}^{*} \leq \bar{q}_{j}\left(p^{*}\right)$ to hold. To show that $q_{j}^{*}=x_{j}$ or $q_{k}^{*}<q_{k s}$ for some marginal firm $k, k \neq j$, are also sufficient conditions to ensure $q_{j}^{*} \leq \bar{q}_{j}\left(p^{*}\right)$, let $\bar{q}_{j}\left(p^{*}\right)<q_{j}^{*} \leq x_{j}$. Consider the deviation by firm $j$ of moving the original bid(s) for quantities in $\left(A, q_{j}^{*}\right]$ above $p^{*}$ (e.g. firm $j$ could bid such quantities at marginal costs). The difference in firm $j$ 's profits is given by

$$
\pi_{j}\left(b^{\prime}\right) \quad \pi_{j}(b)=\left[\begin{array}{ll}
p^{\prime} & p^{*}
\end{array}\right]\left[\begin{array}{ll}
q_{j}^{\prime} & x_{j}
\end{array}\right]+\int_{q_{j}^{\prime}}^{q_{j}^{*}}\left[\begin{array}{ll}
c_{j}(z) & p^{*}
\end{array}\right] d z .
$$

If $q_{k s}<q_{k}^{*}$ let $A=q_{j}^{*} \quad\left[\begin{array}{ll}q_{k s} & q_{k}^{*}\end{array}\right]$. At the resulting bid function profile $b^{\prime}$ the market price remains $p^{*}$ as $j$ 's dispatched output under $b$ is replaced by firm $k$, so that $q_{j}^{\prime}<q_{j}^{*}$. Consequently, the first term in Eq. (S.1) is zero while the second is strictly positive (the deviant now reduces its output and therefore its losses), so that $\pi_{j}\left(b^{\prime}\right)>\pi_{j}(b)$. Since the deviation is profitable, we have reached a contradiction as desired.

If $q_{k s}=q_{k}^{*}$ for all marginal firms $k, k \neq j$, but $q_{j}^{*}=x_{j}$ let $A=q_{j}^{*} \bar{q}_{j}\left(p^{*}\right)$. Now, firm $j$ 's deviation implies a price increase, $p^{\prime}>p^{*}$, thus implying that the first term in Eq. (5) may be negative. However, as we can rewrite Eq. (S.1) as the sum of two integrals, recalling that $q_{j}^{*}=x_{j}$, it follows that

$$
\pi_{j}\left(b^{\prime}\right) \quad \pi_{j}(b)=\int_{x_{j}}^{q_{j}^{\prime}}\left[\begin{array}{ll}
p^{\prime} & p^{*}
\end{array}\right] d z+\int_{q_{j}^{\prime}}^{x_{j}}\left[c_{j}(z) \quad p^{*}\right] d z=\int_{q_{j}^{\prime}}^{x_{j}}\left[c_{j}(z) \quad p^{\prime}\right] d z>0,
$$

since $c_{j}(z)>p^{\prime}$ for all $z \in\left(\bar{q}_{j}\left(p^{*}\right), q_{j}^{*}\right]$ and hence for $z \in\left[q_{j}^{\prime}, x_{j}\right]$. The deviation is again profitable, reaching a contradiction.

Proof of Proposition 1. We must show that $q_{j}^{*} \in\left[q_{j}\left(p^{*}\right), \bar{q}_{j}\left(p^{*}\right)\right]$ for any non price setter firm $j$. By appealing to Lemma 2 it follows that $q_{j}^{*} \geq \underline{q}_{j}\left(p^{*}\right)$ holds. Similarly, if $q_{j}^{*}>x_{j}$ or if $q_{k}^{*}<q_{k s}$ for some marginal firm $k, k \neq j$, then $q_{j}^{*} \leq \bar{q}_{j}\left(p^{*}\right)$ follows from Lemma 3. Thus $q_{j}^{*} \in\left[\underline{q}_{j}\left(p^{*}\right), \bar{q}_{j}\left(p^{*}\right)\right]$ as claimed.

Proof of Proposition 2. (i) We first show that if $D\left(p^{c}\right) \leq \min _{i} \sum_{j \neq i} \bar{q}_{j}\left(p^{c}\right)$ holds, then at any Nash equilibrium $p^{*}=p^{c}$. Assume, by contradiction, that $p^{*}>p^{c}$. Since $p^{*}$ must be set by at least one firm, assume that firm $i$ is a price setter. By Lemma $2, \sum_{j \neq i} q_{j}^{*} \geq \sum_{j \neq i} \underline{q}_{j}\left(p^{*}\right)$, so that $q_{i}^{*}=D\left(p^{*}\right) \quad \sum_{j \neq i} q_{j}^{*} \leq D\left(p^{*}\right) \quad \sum_{j \neq i} \underline{q}_{j}\left(p^{*}\right)$. Furthermore, since $\sum_{j \neq i} \underline{q}_{j}\left(p^{*}\right) \geq \sum_{j \neq i} \bar{q}_{j}\left(p^{c}\right)$, then $q_{i}^{*} \leq D\left(p^{c}\right) \quad \sum_{j \neq i} \bar{q}_{j}\left(p^{c}\right) \leq 0$, contradicting that firm $i$ is a price setter. Since $p^{*}=p^{c}$, it follows that $q_{n}^{*}=q_{n}^{c}$ for all $n$, by Proposition 1.

(ii) [Only if] Assume, by contradiction, that there is a unique price setter, while $p^{*}=p^{c}$ and $q_{n}^{*}=q_{n}^{c}$ for all $n$ hold. Note that by definition of $p^{c}$, it must be the case that $p^{c} \geq c_{n}\left(q_{n}^{c}\right)$. For all the firms that are not marginal such a condition is satisfied with strict inequality, $p^{c}>c_{n}\left(q_{n}^{c}\right)$, so that $q_{n}^{c}=\bar{q}_{n}\left(p^{c}\right)$. Moreover, there must be at least one marginal firm for which 
such a condition is satisfied with equality, $p^{c}=c_{n}\left(q_{n}^{c}\right)$, so that $q_{n}^{c}<\bar{q}_{n}\left(p^{c}\right)$ as we have ruled out the cases under which there is no supply rationing at the competitive outcome. Two possibilities can emerge.

1. Firm $i$ is the unique marginal firm. Hence, $p^{c}=c_{i}\left(q_{i}^{c}\right)$. Firm $i$ can profitably deviate by bidding its marginal output up to $p^{c}+\epsilon$, for $\epsilon$ small enough so that there are no other bids in $\left(p^{c}, p^{c}+\epsilon\right)$. Such a deviation is trivially profitable, $p^{c}=c_{i}\left(q_{i}^{c}\right)$ implies that it was making no profit out of the marginal output.

2. Both firms $i$ and $j$ are marginal. We cannot have $p^{c}=c_{j}\left(q_{j}^{c}\right)=c_{i}\left(q_{i}^{c}\right)$, as both firms would be partly dispatching their marginal steps, which contradicts the fact that there is only one price setter. Hence, let $c_{j}\left(q_{j}^{c}\right)<c_{i}\left(q_{i}^{c}\right)$. If $p^{c}=c_{j}\left(q_{j}^{c}\right)<c_{i}\left(q_{i}^{c}\right)$, firm $i$ would be selling $q_{i}^{c}$ at a price below marginal costs, which is ruled out by weak dominance. Alternatively, if $c_{j}\left(q_{j}^{c}\right)<p^{c}=c_{i}\left(q_{i}^{c}\right)$, both firms must be dispatching their marginal steps as demand would not otherwise be covered, $D\left(p^{c}\right)=\sum_{j \neq i} \bar{q}_{j}\left(p^{c}\right)+q_{i}^{c}$. The contradiction proves our claim.

[If] If there were more than one price setter while $p^{*}>p^{c}$, then $q_{n}^{*} \geq \underline{q}_{n}\left(p^{*}\right)$ for all $n$ must hold by Lemma 2 . Since $q_{n}\left(p^{*}\right) \geq \bar{q}_{n}\left(p^{c}\right) \geq q_{n}^{c}$, then $q_{n}^{*} \geq q_{n}^{c}$ for all $n$. If for at least one of them $q_{n}^{*}>q_{n}^{c}$ holds, then $D\left(p^{*}\right) \geq \sum_{n} q_{n}^{*}>\sum_{n} q_{n}^{c}=D\left(p^{c}\right)$, an impossibility. Consequently, $q_{n}^{*}=q_{n}^{c}$ for all $n$. However, $q_{n}^{*}=q_{n}^{c}$ and $p^{*}>p^{c}$ can only hold simultaneously when $q_{n}^{*}=\bar{q}_{n}\left(p^{*}\right)=\bar{q}_{n}\left(p^{c}\right)=q_{n}^{c}$ for all $n$, so that firms are not rationed at the competitive outcome. A possibility which has been nevertheless ruled out.

Proof of Lemma 4. To show (i), recall that $q_{j}^{*} \geq \underline{q}_{j}\left(p^{*}\right)$ holds for all $j \neq i$ by Proposition 1 . Since $p^{*} \geq p^{c}$, then $\underline{q}_{j}\left(p^{*}\right) \geq \underline{q}_{j}\left(p^{c}\right)$ as $\underline{q}_{j}$ in a non decreasing function of $p$. Consequently, $\pi_{j}^{N P S}\left(p^{*}\right)$ is an increasing function of $p^{*}$ as $q_{j}^{N P S}\left(p^{*}\right) \geq q_{j}^{c}>x_{j}$.

(ii) Since $p^{*} \geq p^{c}$, then $q_{j}^{N P S}\left(p^{*}\right) \geq q_{j}^{c} \geq q_{j}^{P S}\left(p^{*}\right)$, with strict inequality if $p^{*}>p^{c}$. Thus,

$$
\pi_{j}^{N P S}\left(p^{*}\right) \quad \pi_{j}^{P S}\left(p^{*}\right)=\int_{q_{j}^{P S}\left(p^{*}\right)}^{q_{j}^{N P S}\left(p^{*}\right)}\left[p^{*} \quad c_{j}(z)\right] d z \geq 0,
$$

as $p^{*} \geq c_{j}\left(q_{j}^{N P S}\left(p^{*}\right)\right)$.

Proof of Theorem 1. [Only if] Suppose that there exists a pure strategy equilibrium $b$ in which firm $i$ sets the price at $p^{*}=p_{i}^{P S}\left(b_{-i}\right) \geq p^{c}$ and firms' payoffs are $\pi_{i}^{P S}\left(p^{*}\right)$ and $\pi_{j}^{N P S}\left(p^{*}\right), i, j=1, \ldots N, j \neq i$. If this is the case then Condition 1 follows from Proposition 1 and optimal behavior by the price setter, and Conditions 2 and 3 follow trivially from the definition of Nash equilibrium.

[If] To show that no firm profits by deviating from strategies that satisfy Conditions 13 , consider first the non price setters $j, j \neq i$. By Condition 1 , they do not want to change their quantity given $p^{*}$. Thus, the only relevant deviations are those that allow the firm to become the price setter at a price above $p^{*}$. Deviating to a price equal to or lower than $p^{*}$ is not profitable as by Lemma $4, \pi_{j}^{N P S}(p)$ is increasing in $p$ and $\pi_{j}^{N P S}(p) \geq \pi_{j}^{P S}(p)$. Hence, those firms $j$ with $p_{j}^{P S}\left(b_{-j}\right) \leq p^{*}$ will trivially not deviate. Those firms $j$ with $p_{j}^{P S}\left(b_{-j}\right)>p^{*}$ will not deviate as $\pi_{j}^{N P S}\left(p^{*}\right) \geq \pi_{j}^{P S}\left(p_{j}^{P S}\right)$ holds by Condition 3. Last, by Condition 1 the price setter is already maximizing its profits over its residual demand, so that any deviation by firm $i$ must imply becoming a non price setter at a lower price, $p<p^{*}$, while increasing its production to $q_{i}^{N P S}(p)$. Such deviation is not profitable by Condition 2.

Proof of Proposition 3. We first prove part (ii). Let $\hat{b}$ and $b^{\prime}$ be two equilibrium bid profiles such that under $\hat{b}$ all firms $j$ bid at marginal costs (i.e., $\hat{b}_{-i}=c_{-i}$ ) while firm $i$ sets the price at $p^{*}=\hat{p}$, whereas under $b^{\prime}$ at least one firm $j, j \neq i$ does not bid at marginal costs while firm $i$ sets the price at $p^{*}=p^{\prime}$. Trivially, if $\hat{p}=p^{\prime}$ both equilibria are outcome equivalent as prices are the same and firms' $j \neq i$ quantities must also coincide since they must satisfy Proposition 1 . If $\hat{p}>p^{\prime}$ then any non price setter prefers $\hat{b}$ to $b^{\prime}$ as shown in Lemma 4. This is also the case for the price setter: if $p^{\prime}=p^{c}$, the price setter prefers $\hat{p}$ to $p^{\prime}$ by revealed preference, as it could have chosen to also bid at marginal costs to set the price at $p^{c}$, but it chose to set $\hat{p}>p^{c}$ instead; if $p^{\prime}>p^{c}$, then

$$
\pi_{i}^{P S}\left(\hat{p} ; \hat{b}_{-i}\right) \geq \pi_{i}^{P S}\left(p^{\prime} ; \hat{b}_{-i}\right)=\pi_{i}^{P S}\left(p^{\prime} ; b_{-i}^{\prime}\right),
$$

where the first inequality follows from the fact that $\hat{p}$ is an equilibrium under $\hat{b}$ which requires that $\hat{p} \in \arg \max _{p} \pi_{i}^{P S}\left(p ; \hat{b}_{-i}\right)$, and the second equality from the fact that $p^{\prime}$ is an equilibrium under $b^{\prime}$ so that Proposition 1 holds and hence $q_{j}^{*}\left(p^{\prime} ; b_{-i}^{\prime}\right)=q_{j}^{*}\left(p^{\prime} ; \hat{b}_{-i}\right)=q_{j}^{*}\left(p^{\prime} ; c_{-i}\right)$ for all $j \neq i$ so that $q_{i}^{*}\left(p^{\prime} ; b_{-i}^{\prime}\right)=q_{i}^{*}\left(p^{\prime} ; \hat{b}_{-i}\right)$. Since all firms are better off at $\hat{b}=\left(\hat{b}_{i}, c_{-i}\right)$, it is the Pareto dominant one, as claimed.

If $\hat{p}<p^{\prime}$, we show next that $p^{\prime}$ is also an equilibrium under $\hat{b}$. For the sake of contradiction assume it is not so that one of the three conditions in Theorem 1 must fail to hold. Since firms $j \neq i$ bid at marginal costs, they are trivially producing optimally conditionally on being non price setters; furthermore, given that the non price setters do not want to become the price setter under $\hat{p}, \hat{p}<p^{\prime}$, the same must hold true under $p^{\prime}$ so that Condition 3 of Theorem 1 is satisfied. As $p^{\prime}$ is an equilibrium under $b^{\prime}$ then for any $p \leq p^{\prime}$ such that $\sum_{n} q_{n}\left(p ; b_{-i}^{\prime}\right)=D(p)$,

$$
\pi_{i}^{P S}\left(p^{\prime} ; b_{-i}^{\prime}\right)=\pi_{i}^{P S}\left(p^{\prime} ; \hat{b}_{-i}\right) \geq \pi_{i}^{N P S}\left(p ; b_{-i}^{\prime}\right)=\pi_{i}^{N P S}\left(p ; \hat{b}_{-i}\right),
$$

where the first equality and second inequality follow from the fact that $p^{\prime}$ is an equilibrium under $b^{\prime}$ (so that Conditions 1 and 2 in Theorem 1 hold) and the last equality from the fact that the non price setters' profits are independent of their rivals' strategies. Hence, since this implies that Condition 2 of Theorem 1 does also hold, it must then be the case that 
$p^{\prime} \notin \arg \max \pi_{i}^{P S}\left(\hat{b}_{-i}\right)$, so that

$$
\pi_{i}^{P S}\left(\hat{p} ; \hat{b}_{-i}\right)>\pi_{i}^{P S}\left(p^{\prime} ; \hat{b}_{-i}\right)=\pi_{i}^{P S}\left(p^{\prime} ; b_{-i}^{\prime}\right) \geq \pi_{i}^{P S}\left(\hat{p} ; b_{-i}^{\prime}\right)
$$

where the last inequality from the fact that $p^{\prime} \in \arg \max \pi_{i}^{P S}\left(b_{-i}^{\prime}\right)$. Thus, $\pi_{i}^{P S}\left(\hat{p} ; \hat{b}_{-i}\right)>\pi_{i}^{P S}\left(\hat{p} ; b_{-i}^{\prime}\right)$ or equivalently,

$$
\int_{q_{i}\left(\hat{p} ; b^{\prime}{ }_{i}\right)}^{q_{i}\left(\hat{p} ; \hat{b}^{i}\right)}\left[\hat{p} \quad c_{i}(z)\right] d z>0 .
$$

However, integral above cannot be positive. If $q_{i}\left(\hat{p} ; b_{-i}^{\prime}\right)=q_{i}\left(\hat{p} ; \hat{b}_{-i}\right)$, integral above is zero. If $q_{i}\left(\hat{p} ; b_{-i}^{\prime}\right)>q_{i}(\hat{p} ; \hat{b}-i)$, because some bidder $j$ bids units above marginal costs, then $\hat{p} \geq c_{i}\left(q_{i}\left(\hat{p} ; b_{-i}^{\prime}\right)\right.$ ) implies that the integral is negative. (c) Finally, if $q_{i}\left(\hat{p} ; b_{-i}^{\prime}\right)<q_{i}\left(\hat{p} ; \hat{b}_{-i}\right)$ then some bidder $j$ bids units below marginal costs at $b_{-i}^{\prime}$. Since such units are dispatched under $\hat{b}-i$ bidding them below marginal costs is ruled out by weak dominance so that $q_{i}\left(\hat{p} ; b_{-i}^{\prime}\right)<q_{i}(\hat{p} ; \hat{b}-i)$ cannot hold in equilibrium. Since integral above cannot be positive we ran into a contradiction proving that $p^{\prime}>\hat{p}$ must also be an equilibrium when firms $j$ bid at marginal costs as it satisfies the three conditions in Theorem 1 . Last, by the same arguments as above, the equilibrium with $p^{\prime}$ Pareto dominates the equilibrium with $\hat{p}$.

We now prove (i). The [If] part is trivial, so we omit it. [Only If] For the sake of contradiction, suppose that the equilibrium in which firm $i$ is the price setter at $p^{*}=p_{i}^{P S}\left(c_{-i}\right)$ while all other firms bid at marginal costs does not exist. This must be because Condition 3 fails to hold, given that Conditions 1 and 2 trivially hold. If there is multiple profit maximizing prices any other price $p^{*} \in \arg \max \pi_{i}^{P S}\left(c_{-i}\right)<p_{i}^{P S}\left(c_{-i}\right)$ would also violate Condition 3, given that $p_{i}^{P S}\left(c_{-i}\right)$ is assumed to be the largest one. To show that there does not exist any other equilibrium in which firm $i$ is the price setter, argue by contradiction and suppose that some other bid profile $b^{\prime}$ constitutes an equilibrium. If $p^{\prime}<p_{i}^{P S}\left(c_{-i}\right)$ then Condition 3 will again fail to hold contradicting that it constitutes an equilibrium, whereas if $p^{\prime}>p_{i}^{P S}\left(c_{-i}\right)$ then $p^{\prime}$ must also be sustainable when the non price setters bid at marginal costs as shown in (ii). The contradiction proves the claim.

Proof of Proposition 4. Let us first introduce the following piece of notation. For $x_{n} \geq x_{j}=0$, let $x_{n}^{\prime}$ be the smallest amount of contracts held by firm $n$ for which the equilibrium in which firm $n$ sets the price does not exist. Formally,

$$
x_{n}^{\prime} \equiv \min \left\{x_{n}: x_{n} \in\left[0, q_{n}^{c}\right] \text { and } \pi_{j}^{N P S}\left(p_{n}^{P S}\left(x_{n}\right)\right)<\pi_{j}^{P S}\left(p_{j}^{P S}(0)\right) \text { for some } j\right\} \text {. }
$$

(i) By construction, $p_{1}^{P S}(0)$ is the highest candidate equilibrium price at the no contracts case, and Corollary 1 guarantees that it is an equilibrium price. Since $p_{1}^{P S}\left(x_{1}\right)$ is weakly decreasing in $x_{1}$, the highest equilibrium price when $x_{1}>0$ is $\max \left\{p_{1}^{P S}\left(x_{1}\right), p_{2}^{P S}(0)\right\} \leq p_{1}^{P S}(0)$. Hence, the highest equilibrium price is (weakly) higher at the no contracts case. To show that the lowest equilibrium price is also (weakly) higher at the no contracts case, let $p_{i}^{P S}(0)$ be the lowest equilibrium price when $x_{1}=0$. By Corollary 2 , any price $p_{n}^{P S}(0) \geq p_{i}^{P S}(0)$, for $1<n \leq i$, must also be an equilibrium price when $x_{1}=0$ as well as when $x_{1}>0$. The incentives of all firms other than firm 1 do not depend on $x_{1}$, whereas firm 1 's incentives to deviate from an equilibrium in which firm $n$ sets the price are decreasing in $x_{1}$; hence, if no firm deviates from $p_{n}^{P S}(0)$ when $x_{1}=0$, no firm will deviate either when $x_{1}>0$. It thus follows that the lowest equilibrium price when $x_{1}>0$ cannot be larger than $p_{i}^{P S}(0)$. Therefore, since the set of equilibrium prices is the same when $x_{1}=0$ or $x_{1}>0$, except (possibly) for the highest price, which is higher when $x_{1}=0$, and the lowest(s) price(s) which is (possibly) lower when $x_{1}>0$, contracts by firm 1 only (weakly) reduce prices.

Let us now show that there can exist a non monotonic relationship between contracts awarded to firm 1 and equilibrium prices. Since $p_{1}^{P S}(0)$ is an equilibrium price when $x_{1}=0$, while when $x_{1}=q_{1}^{c}$ it is not $\left(\right.$ since $p_{1}^{P S}\left(q_{1}^{c}\right) \leq p^{c}<p_{2}^{P S}(0)$, firm 2 would trivially deviate from such a low price), there exists $x_{1}^{\prime} \in\left(0, q_{1}^{c}\right]$ such that the equilibrium with $p_{1}^{P S}\left(x_{1}\right)$ does not exist for all $x_{1} \in\left[x_{1}^{\prime}, q_{1}^{c}\right]$. Let $p_{j}^{P S}(0)$ be the lowest equilibrium price when $x_{1}=x_{1}^{\prime}$. By Corollary 2 , it must be the case that $p_{1}^{P S}\left(x_{1}^{\prime}\right)<p_{j}^{P S}(0)$ as otherwise $p_{1}^{P S}\left(x_{1}^{\prime}\right)$ would also be an equilibrium. Thus, if $p_{1}^{P S}\left(x_{1}\right)$ is close enough to $p_{1}^{P S}\left(x_{1}^{\prime}\right)$ for $x_{1}$ slightly below $x_{1}^{\prime}$, then equilibrium prices go up as $x_{1}$ approaches $x_{1}^{\prime}$. Note that such non monotonicity need not always arise, e.g. if for $x_{1}$ slightly below $x_{1}^{\prime}, p_{1}^{P S}\left(x_{1}\right) \geq p_{j}^{P S}(0)$.

(ii) Let us allocate all contracts to firm $i$. Since $p_{i}^{P S}(0)$ is the lowest equilibrium price at the no contracts case, by Corollary 2 , equilibrium prices are $\left\{p_{1}^{P S}(0), \ldots, p_{i-1}^{P S}(0), p_{i}^{P S}(0)\right\}$. Existence of $x_{i}^{\prime} \in\left(0, q_{i}^{c}\right]$ is guaranteed by monotonicity, since $p_{i}^{P S}(0)$ is an equilibrium price while $p_{i}^{P S}\left(q_{i}^{c}\right) \leq p^{c}<p_{1}^{P S}(0)$ is not (firm 1 would trivially deviate from such a low price). Now, as $p_{i}^{P S}\left(x_{i}\right)$ is non increasing in $x_{i}$, allocating contracts $x_{i} \in\left(0, x_{i}^{\prime}\right)$ to firm $i$ leads to (weakly) lower prices as compared to the no contracts case, as equilibrium prices are $\left\{p_{1}^{P S}(0), \ldots, p_{i-1}^{P S}(0), p_{i}^{P S}\left(x_{i}\right)\right\}$ and $p_{i}^{P S}(0) \geq p_{i}^{P S}\left(x_{i}\right)$. However, allocating contracts $x_{i} \in\left[x_{i}^{\prime}, q_{i}^{c}\right]$ yields to (weakly) higher prices, as equilibrium prices are $\left\{p_{1}^{P S}(0), \ldots, p_{i-1}^{P S}(0)\right\}$ and $p_{i}^{P S}(0) \leq p_{i-1}^{P S}(0)$. Note that allocating contracts $x_{i}$ to firm $i$ does not give rise to new equilibria in which firms $n>i$ set prices, as at least firm 1 would deviate from such equilibria. It follows that there exists a (weak) non monotonic relationship between contract volume and equilibrium prices when contracts are awarded to firm $i$.

Similar arguments would imply that if all contracts are awarded to some firm $1<n<i$, there exists $x_{n}^{\prime} \in\left(0, q_{n}^{c}\right)$ such that equilibrium prices are $\left\{p_{1}^{P S}(0), \ldots, p_{n}^{P S}\left(x_{n}\right), \ldots, p_{i}^{P S}(0)\right\}$ for $x_{n}<x_{n}^{\prime}$ and $\left\{p_{1}^{P S}(0), \ldots, p_{n-1}^{P S}(0), p_{n+1}^{P S}(0), \ldots, p_{i}^{P S}(0)\right\}$ for $x_{n} \geq x_{n}^{\prime}$. Contracts $x_{n}<x_{n}^{\prime}$ thus lead to (weakly) lower prices, but the effect of contracts $x_{n} \geq x_{n}^{\prime}$ depends on which equilibrium is chosen, given that $p_{i}^{P S}(0) \leq p_{n}^{P S}(0) \leq p_{1}^{P S}(0)$.

(iii) Since for $n>i, p_{n}^{P S}(0)$ is not an equilibrium price at the no contracts case, it follows that $x_{n}^{\prime}=0$. Consequently, for any $x_{n} \geq 0, p_{n}^{P S}\left(x_{n}\right) \leq p_{n}^{P S}(0)$, so that by Corollary $2, p_{n}^{P S}\left(x_{n}\right)$ cannot be sustained in equilibrium. Hence, prices remain the same as in the no contracts case. 
Proof of Lemma 6. Since marginal costs are zero, $p_{i}^{P S}\left(x_{i}\right)=\arg \max _{p}\left\{p\left[D(p) \quad K_{j} \quad x_{i}\right]\right\}$ for $i=1,2$. It follows from the implicit function theorem that $p_{i}^{P S}\left(x_{i}\right)$ is decreasing in $x_{i}$ and $K_{j}$. Thus, $K_{1}>K_{2}$ and $x_{2}>0=x_{1}$ imply $p_{1}^{P S}(0)>p_{2}^{P S}(0)>p_{2}^{P S}\left(x_{2}\right)$. Similarly, since $p_{1}^{P S}(0)$ is increasing in $\alpha$ and it is independent of $x_{2}$, whereas $p_{2}^{P S}\left(x_{2}\right)$ is decreasing in $\alpha$ and $x_{2}$, it follows that $p_{1}^{P S}(0)$ $p_{2}^{P S}\left(x_{2}\right)>0$ is increasing in $\alpha$ and $x_{2}$. Last, from $p_{1}^{P S}(0)>p_{2}^{P S}\left(x_{2}\right)$, it follows that the equilibrium with $p_{1}^{P S}(0)$ exists for all $\alpha$ (Corollary 1 ).

We need to show that there exists $\widehat{\alpha}\left(x_{2}\right)$ above which the equilibrium with $p_{2}^{P S}\left(x_{2}\right)$ does not exist. At $x_{2}=0$ it follows trivially that $\widehat{\alpha}(0)=D(0) / K>1 / 2$. To see this just note that for $\alpha \geq D(0) / K$, the residual demand faced by firm 2 would be non positive, $D(p) \quad K_{1}<D(0) \quad \alpha K \leq 0$. Since $p_{2}^{P S}(0)=p^{c}=0$, firm 2 cannot be a price setter as firm 1 would rather deviate. In contrast, for any $\alpha<\widehat{\alpha}(0)=D(0) / K$, we have that $\pi_{1}^{N P S}\left(p_{2}^{P S}(0)\right) \pi_{1}^{P S}\left(p_{1}^{P S}(0)\right)=p_{2}^{P S}(0)\left[K \quad D\left(p_{1}^{P S}(0)\right)\right]>0$ so that $\left\{p_{1}^{P S}(0), p_{2}^{P S}(0)\right\}$ are both equilibrium prices.

For $x_{2}>0$, firm 2 cannot be the price setter for any $\alpha \geq \widehat{\alpha}\left(x_{2}\right)$, where $\widehat{\alpha}\left(x_{2}\right)$ is implicitly defined as the solution to $\pi_{1}^{N P S}\left(p_{2}^{P S}\left(x_{2}\right)\right)=\pi_{1}^{P S}\left(p_{1}^{P S}(0)\right)$, i.e.,

$$
\alpha K p_{2}^{P S}\left(x_{2}\right)=\left[\begin{array}{lll}
D\left(p_{1}^{P S}(0)\right) & (1 & \alpha
\end{array}\right) p_{1}^{P S}(0),
$$

with both $p_{2}^{P S}(0)$ and $p_{2}^{P S}\left(x_{2}\right)$ depending on $\alpha$. For any $\alpha>\widehat{\alpha}\left(x_{2}\right)$ firm 2 cannot be the price setter as the necessary condition in Theorem 1 (point 3) would not be satisfied. Finally, $\widehat{\alpha}\left(x_{2}\right)$ is decreasing in $x_{2}$ as $p_{2}^{P S}\left(x_{2}\right)$ is decreasing in $x_{2}$.

\section{Appendix B. Supplementary material}

Supplementary data associated with this article can be found in the online version at doi:10.1016/j.euroecorev.2011.11.005.

\section{References}

Allaz, B., Vila, J.-L., 1993. Cournot competition, forwards markets and efficiency. Journal of Economic Theory 59, 1-16. Ausubel, L., Cramton, P., 2002. Demand Reduction and Inefficiency in Multi-Unit Auctions. Working Paper 96-07. University of Maryland. Ausubel, L.M., Cramton, P., 2010. Virtual power plant auctions. Utilities Policy 18, 201-208.

Back, K., Zender, J., 1993. Auctions of divisible goods: on the rationale for the Treasury experiment. Review of Financial Studies 6, 733-764. Bernheim, B.D., Peleg, B., Whinston, M.D., 1987. Coalition-proof Nash equilibria. I. Concepts. Journal of Economic Theory 42, 1-12.

Borenstein, S., 1996. Settling for coupons: discount contracts as compensation and punishment in antitrust lawsuits. Journal of Law and Economics 39, 379-404.

Borenstein, S., Bushnell, J., Wolak, F., 2002. Measuring market inefficiencies in California's restructured wholesale electricity market. American Economic Review 92 (5), 1376-1405.

Bushnell, J., 2007. Oligopoly equilibria in electricity contract markets. Journal of Regulatory Economics 32, 225-245.

Bushnell, J., Mansur, E., Saravia, C., 2008. Vertical arrangements, market structure and competition: an analysis of restructured U.S. electricity markets. American Economic Review 98, 237-266.

Crawford, G.S., Crespo, J., Tauchen, H.V., 2007. Bidding asymmetries in multi-unit auctions: implications of bid function equilibria in the British spot market for electricity. International Journal of Industrial Organization 25, 1233-1268.

Fabra, N., von der Fehr, N.H., de Frutos, M.A., 2011. Market design and investment incentives. Economic Journal 121, 1340-1360.

Fabra, N., von der Fehr, N.H., Harbord, D., 2006. Designing electricity auctions. Rand Journal of Economics 37, 23-46.

Fabra, N., Toro, J., 2005. Price wars and collusion in the Spanish electricity market. International Journal of Industrial Organization 23, 155-181.

Federico, G., López, A., 2009. Divesting Power. Mimeo. IESE Business School.

von der Fehr, N.-H., Harbord, D., 1993. Spot market competition in the UK electricity industry. Economic Journal 103, 531-546.

Ferreira, J.L., 2003. Strategic interaction between futures and spot markets. Journal of Economic Theory 108, 141-151.

García-Díaz, A., Marín, P., 2003. Strategic bidding in electricity pools with short-lived bids: an application to the Spanish market. International Journal of Industrial Organization 21, 201-222.

Green, R.J., 1999. The electricity contract market in England and Wales. Journal of Industrial Economics 47, 107-124.

Green, R.J., Le Coq, C., 2010. The length of contracts and collusion. International Journal of Industrial Organization 28, 21-29.

Holmberg, P., 2011. Strategic forward contracting in the wholesale electricity market. Energy Journal 32, 169-202.

Hortacsu, A., Puller, S., 2008. Understanding strategic bidding in multi-unit auctions: a case study of the Texas electricity spot market. Rand Journal of Economics 39, 86-114.

Kastl, J., 2011. On the Properties of Equilibria in Private Value Divisible Good Auctions with Constrained Bidding. Mimeo. Stanford University.

Klemperer, P., 2003. Alfred Marshall lecture: using and abusing economic theory. Journal of the European Economic Association 1, 272-300.

Klemperer, P.D., Meyer, M.A., 1989. Supply function equilibria in oligopoly under uncertainty. Econometrica 57, 1243-1277.

Kremer, I., Nyborg, K.G., 2004. Underpricing and market power in uniform-price auctions. Review of Financial Studies 17, $849-877$.

Kühn, K.-U., Machado, M., 2006. Bilateral Market Power and Vertical Integration in the Spanish Electricity Spot Market. CEPR Discussion Paper N. 4590.

Liski, M., Montero, J.P., 2006. Forward trading and collusion in oligopoly. Journal of Economic Theory 131, 212-230.

Mahenc, P., Salanié, F., 2004. Softening competition through forward trading. Journal of Economic Theory 116, $282-293$.

Mansur, E.T., 2007. Upstream competition and vertical integration in electricity markets. Journal of Law and Economics 50, 125-156.

Newbery, D.M., 1998. Competition, contracts, and entry in the electricity spot market. Rand Journal of Economics 29, 726-749.

Nyborg, K.G., Strebulaev, I.A. 2004. Multiple unit auctions and short squeezes. The Review of Financial Studies 17, 545-580.

Schultz, C., 2009. Virtual Capacity and Competition. Mimeo. University of Copenhagen.

Wilson, R., 1979. Auctions of shares. Quarterly Journal of Economics 93, 675-689.

Wolak, F.A., 2000. An empirical analysis of the impact of hedge contracts on bidding behavior in a competitive electricity market. International Economic Journal 14, 1-39.

Wolak, F.A., 2007. Quantifying the supply-side benefits from forward contracting in wholesale electricity markets. Journal of Applied Econometrics 22 1179-1209.

Wolak, F.A., 2012. Regulating competition in wholesale electricity supply. In: Rose, N. (Ed.), Economic Regulation and Its Reform: What Have We Learned? The University of Chicago Press.

Wolfram, C.D., 1999. Measuring duopoly power in the British electricity spot market. American Economic Review 89, 805-826. 